\title{
Early lysosomal maturation deficits in microglia triggers enhanced lysosomal activity in other brain cells of progranulin knockout mice
}

Julia K. Götzl ${ }^{1 \dagger}$, Alessio-Vittorio Colombo ${ }^{2 \dagger}$, Katrin Fellerer ${ }^{1 \dagger}$, Anika Reifschneider ${ }^{1}$, Georg Werner ${ }^{1}$, Sabina Tahirovic ${ }^{2}$, Christian Haass ${ }^{1,2,3^{*}}$ and Anja Capell ${ }^{1 *}$ (D)

\begin{abstract}
Background: Heterozygous loss-of-function mutations in the progranulin gene (GRN) lead to frontotemporal lobar degeneration (FTLD) while the complete loss of progranulin (PGRN) function results in neuronal ceroid lipofuscinosis (NCL), a lysosomal storage disease. Thus the growth factor-like protein PGRN may play an important role in lysosomal degradation. In line with a potential lysosomal function, PGRN is partially localized and processed in lysosomes. In the central nervous system (CNS), PGRN is like other lysosomal proteins highly expressed in microglia, further supporting an important role in protein degradation. We have previously reported that cathepsin (Cat) D is elevated in GRN-associated FTLD patients and Grn knockout mice. However, the primary mechanism that causes impaired protein degradation and elevated CatD levels upon PGRN deficiency in NCL and FTLD remains unclear.

Methods: mRNA expression analysis of selected lysosomal hydrolases, lysosomal membrane proteins and autophagyrelated genes was performed by NanoString nCounter panel. Protein expression, maturation and in vitro activity of Cat D, $B$ and $L$ in mouse embryonic fibroblasts (MEF) and brains of Grn knockout mice were investigated. To selectively characterize microglial and non-microglial brain cells, an acutely isolated microglia fraction using MACS microbeads (Miltenyi Biotec) conjugated with CD11b antibody and a microglia-depleted fraction were analyzed for protein expression and maturation of selected cathepsins.

Results: We demonstrate that loss of PGRN results in enhanced expression, maturation and in vitro activity of Cat $D, B$ and $L$ in mouse embryonic fibroblasts and brain extracts of aged Grn knockout mice. Consistent with an overall enhanced expression and activity of lysosomal proteases in brain of Grn knockout mice, we observed an age-dependent transcriptional upregulation of certain lysosomal proteases. Thus, lysosomal dysfunction is not reflected by transcriptional downregulation of lysosomal proteases but rather by the upregulation of certain lysosomal proteases in an agedependent manner. Surprisingly, cell specific analyses identified early lysosomal deficits in microglia before enhanced cathepsin levels could be detected in other brain cells, suggesting different functional consequences on lysosomal homeostasis in microglia and other brain cells upon lack of PGRN.

(Continued on next page)
\end{abstract}

\footnotetext{
*Correspondence: christian.haass@mail03.med.uni-muenchen.de; anja.capell@mail03.med.uni-muenchen.de

†Julia K. Götzl, Alessio-Vittorio Colombo and Katrin Fellerer contributed equally to this work.

${ }^{1}$ Chair of Metabolic Biochemistry, Biomedical Center (BMC), Faculty of

Medicine, Ludwig-Maximilians-Universität München, 81377 Munich, Germany

Full list of author information is available at the end of the article
}

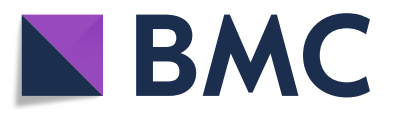

(c) The Author(s). 2018 Open Access This article is distributed under the terms of the Creative Commons Attribution 4.0 International License (http://creativecommons.org/licenses/by/4.0/), which permits unrestricted use, distribution, and reproduction in any medium, provided you give appropriate credit to the original author(s) and the source, provide a link to the Creative Commons license, and indicate if changes were made. The Creative Commons Public Domain Dedication waiver (http://creativecommons.org/publicdomain/zero/1.0/) applies to the data made available in this article, unless otherwise stated. 
(Continued from previous page)

Conclusions: The present study uncovers early and selective lysosomal dysfunctions in Grn knockout microglia/

macrophages. Dysregulated lysosomal homeostasis in microglia might trigger compensatory lysosomal changes in other brain cells.

Keywords: Frontotemporal lobar degeneration, Microglia, Neurodegeneration, Progranulin, Lysosome, Cathepsin

\section{Background}

Pathogenic mutations in the progranulin gene $(G R N)$ are genetically linked to frontotemporal lobar degeneration (FTLD) and a rare adult-onset form of neuronal ceroid lipofuscinosis (NCL) [1-4]. Haploinsufficiency caused by non-sense and a few missense mutations result in GRN-associated FTLD (FTLD/GRN) [1, 2, 5-7] while homozygous loss-of-function GRN mutation carriers, who completely loose progranulin (PGRN) expression, develop NCL [3, 4]. Gene mutations causative for the different NCL forms are mostly associated with the lysosomal degradation pathway [8], indicating that PGRN may also be involved in lysosomal function. Indeed, Grn knockout mice are characterized by an increase of lysosomal proteins, NCL-like storage material, lipofuscinosis and an accumulation of the autophagy markers ubiquitin and p62 [3, 9-14]. Beside the genetic link between PGRN and lysosomal disorders [3, 4], there is also increasing evidence supporting lysosomal dysfunction in FTLD [15]. Hallmarks of all FTLD/GRN patients are cytoplasmic inclusions of hyperphosphorylated TAR DNA binding protein (TDP)-43 co-localizing with ubiquitin and p62 $[16,17]$. Furthermore, FTLD/GRN patients show symptoms typically associated with $\mathrm{NCL}$, like retinal thinning, lipofuscin and NCL-like storage material deposits [18-21]. Finally, challenging lysosomes by starvation, sucrose treatment, inhibition of vacuolar ATPase or alkalizing drugs causes an increase in PGRN production [21-23]. PGRN is a multifunctional complex glycosylated protein, which can be secreted as a growth factor into the extracellular space [24-26]. Secreted PGRN is also processed to granulin peptides by several different proteases including matrix metalloproteinases -9 and -14 [27, 28], a disintegrin and metalloproteinase with thrombospondin motif 7 (ADAMTS-7) [29], neutrophil elastase, proteinase 3 [25, 30], and intracellular by cathepsin L (Cat L) [31, 32]. Additionally, PGRN can be transported to lysosomes using two distinct transport pathways; one mediated by the sortilin receptor [33] and the other one via complex formation with prosaposin. Prosaposin is then transported to lysosomes by binding to the mannose-6-phosphate receptor or the low density lipoprotein receptor-related protein 1 [34]. Recent evidence indicates that lysosomal localized PGRN [33, 3537] may function in lysosomal homeostasis and autophagy [38-40]. Additionally, granulin peptides, which are generated within lysosomes [31, 32, 41], might affect the lysosomal function [38].
To further understand if and how the loss of PGRN may cause lysosomal dysfunction we searched for changes in protein expression, maturation and enzymatic activity of a subset of lysosomal cathepsins in microglia and other brain cells. Microglia, which are the main source of PGRN in the brain, showed a severe impairment of lysosomal cathepsin expression and maturation in the absence of PGRN whereas the remaining brain cells showed increased cathepsin processing and maturation. We therefore propose different effects on lysosomal function upon loss of PGRN in microglia and other brain cells like astrocytes and neurons.

\section{Methods}

Animal experiments and mouse brain tissue

All animal experiments were performed in accordance with local animal handling laws. Mice were sacrificed by $\mathrm{CO}_{2}$ inhalation. Brain tissue was obtained from the $\mathrm{Grn}^{-1-}$ mouse strain generated by Kayasuga and colleagues [42].

\section{Isolation of adult primary microglia, neurons and astrocytes}

Primary microglia were isolated from adult mouse brain using MACS Technology (Miltenyi Biotec) according to manufacturer's instructions. Briefly, brain cortices were dissected, and after removal of meninges dissociated by enzymatic digestion using the Neural Tissue Dissociation Kit P (Miltenyi Biotec). CD11b-positive microglia were magnetically labelled with CD11b MicroBeads, loaded onto a MACS Column (Miltenyi Biotec) and subjected to magnetic separation. Isolated microglia and the microglia depleted fraction were snap frozen in liquid nitrogen and stored at $-80{ }^{\circ} \mathrm{C}$ until further biochemical analysis. To determine PGRN expression in different brain cell types, microglial, neuronal and astrocytic cells, the dissected mouse brain, after removal of meninges, was dissociated by using the Adult Brain Dissociation Kit (Miltenyi Biotec). A single cell suspension was generated according to the manufactures instructions with the exception that the mouse brain was mechanically dissociated by using in sequence, three fire-polished Pasteur pipettes with decreasing tip diameters. The single cell suspension of five mice were combined and separated in three aliquots for isolating microglia cells (Anti-CD11b MicroBeads, Miltenyi Biotec), astrocytes (Anti-ACSA-2 
MicroBeads, Miltenyi Biotec) and neurons (Neuron Isolation Kit, Miltenyi Biotec) according to the manufactures instructions. Isolated cells were snap frozen in liquid nitrogen and stored at $-80{ }^{\circ} \mathrm{C}$ until further biochemical analysis.

\section{Generation and culturing of mouse embryonic fibroblasts (MEF) lines}

$\mathrm{Ctsd}^{-/-}$MEF were provided by Dr. Paul Saftig and generated from the Ctsd knockout mouse strain [43]. For $\mathrm{Grn}^{-1-} \mathrm{MEF}$, timed pregnant female of a heterozygous Grn mating was sacrificed by $\mathrm{CO}_{2}$ inhalation, the embryos (E15) were processed and MEF were separated by digestion with trypsin-EDTA [44]. MEF cells with the same genotype derived from littermates were pooled and immortalized by serial (3 T3) passaging [44]. From immortalized MEF either single cell clones were isolated or pools were generated. For rescue of PGRN deficiency, $\mathrm{Grn}^{-/-}$MEF were transfected with mGrn cloned into the HindIII and XhoI site of pcDNA3.1 (Hygro+) and selected with hygromycin B at $50 \mathrm{mg} / \mathrm{mL}$ (Invitrogen). Single cell clones were analyzed for PGRN expression. MEF were cultured in DMEM with Glutamax I (Invitrogen) supplemented with $10 \%$ fetal calf serum (Invitrogen) and penicillin/streptomycin (PAA Laboratories).

\section{Quantitative NanoString nCounter gene expression assay}

NanoString nCounter technology allows expression analysis of multiple genes from a single sample. We generated an nCounter panel for analyzing gene expression of 45 lysosomal and autophagy- related genes [45-48] and 5 housekeeping genes. Total RNA was extracted from aliquots of powdered mouse brain samples using QIAshredder and RNeasy Mini Kit (Qiagen). 100 ng RNA per brain was used for gene expression analysis. The NanoString panel measurement and evaluation was done at Proteros Biostructures $\mathrm{GmbH}$, Martinsried, Germany. Gene expression levels in each sample were normalized against the geometric mean of four housekeeping genes including Cltc, Hprt, Pgk1 and Tubb5 using nSolver ${ }^{\text {rm }}$ Analysis Software, version 3.0 (NanoString Technologies, Inc.) Gusb was excluded because of significant changes of expression in $\mathrm{Grn}^{-1-}$ mice. Based on the normalized gene expression levels of $\mathrm{Gr}^{-/-}$and $\mathrm{Gr}^{+/+}(n=3)$, statistical significance was determined by the unpaired, two-tailed student's t-test.

\section{Quantitative real time PCR (qRT-PCR)}

Approximately $10-20 \mathrm{mg}$ of powdered mouse brain homogenates were subjected to total RNA preparation using the QIAshredder and RNeasy Mini Kit (Qiagen) according to manufacturer's instructions. $2 \mu \mathrm{g}$ of RNA was reverse transcribed into cDNA using M-MLV reverse transcriptase (Promega) and oligo $(\mathrm{dT})$ primers
(Life Technologies). The following primer sets from Integrated DNA Technologies were used: mouse Ctsd Mm.PT.53a.17202883 (Exon boundary 3 to 4), mouse Ctsb Mm.PT.53a.7639164 (Exon boundary 4 to 5), mouse Ctsl Mm.PT.58.9857472 (Exon boundary 7 to 8), mouse App Mm00431827_m1 (Applied Biosystems) and mouse Gapdh Mm.PT.39a.1 (Exon boundary 2 to 3). cDNA levels were quantitatively determined in triplicates using TaqMan assays on a 7500 Fast Real-Time-PCR System (Applied Biosystems). All cDNA levels were normalized to Gapdh cDNA and relative transcription levels of the respective sequences were analyzed using the comparative delta Ct method (7500 Software V2.0.5, Applied Biosystems, Life Technologies).

\section{Antibodies}

The following primary antibodies were used for immunoblotting: mouse monoclonal anti- $\beta$-actin antibody (Sigma-Aldrich; 1:10,000), mouse monoclonal anti- $\alpha$-tubulin antibody (Sigma-Aldrich; 1:5,000), goat anti-cathepsin D (sc-20) antibody (Santa Cruz Biotechnology; 1:500), goat anti-cathepsin B (AF965) antibody (R\&D Systems; 0,1 $\mu \mathrm{g} /$ $\mathrm{ml}$ ), goat anti-cathepsin L (AF1515) antibody (R\&D Systems; $1 \mu \mathrm{g} / \mathrm{ml}$ ), goat anti-cathepsin S (M-19) antibody (Santa Cruz Biotechnology; 1:200), rat anti-PGRN (8H10) antibody (1:50) [18]; rabbit anti-GFAP antibody (Dako; 1:5,000), rabbit anti-Iba1 antibody (Dako; 1:1000), rabbit anti-neuronal class III ß-Tubulin (Tuj1) antibody (BioLegend; 1:10,000), rabbit anti-p62/SQSTM1 antibody (MBL; 1:1,000), mouse anti-ubiquitin (P4D1) antibody (Santa Cruz Biotechnology; 1:1000), rabbit anti-APP (Y188) antibody (Abcam, 1:2,000) rat monoclonal anti-mLamp1 antibody clone 1D4B (developed by J. Thomas August, distributed by Developmental Studies Hybridoma Bank, NICHD, maintained by the University of Iowa, Department of Biology; 1:200), goat polyclonal anti-saposin $\mathrm{D}$ antibody $(1: 1,000)$ [49], and rabbit anti-LC3BB/MAP1LC3B antibody (Novus Biologicals; $2 \mu \mathrm{g} / \mathrm{ml}$ ). The following secondary antibodies were used: horseradish peroxidase-conjugated donkey anti-goat IgG (Santa Cruz Biotechnology; 1:5,000), anti-mouse IgG (Promega; 1:10,000), anti-rabbit IgG (Promega; 1:20,000), goat anti-rat IgG + IgM $(L+M)$ (Dianova; $1: 5,000)$ and generated mouse anti-rat IgG2c $(1: 1,000)$.

\section{Protein analysis and immunoblotting}

For microglia, neurons and astrocytes cell pellets were lysed in RIPA buffer [18] supplemented with protease inhibitor cocktail (Sigma-Aldrich) and phosphatase inhibitor (Roche Applied Science) and centrifuged for $30 \mathrm{~min}$, $15,000 \times \mathrm{g}, 4{ }^{\circ} \mathrm{C}$. MEF cells were lysed in RIPA buffer $(150 \mathrm{mM} \mathrm{NaCl}, 50 \mathrm{mM}$ TRIS pH 8.0; 0.1\% SDS, $1 \%$ NP40, 0.5\% Sodiumdeoxycholat) supplemented with Benzonase (Novagen), protease inhibitor cocktail (Sigma-Aldrich) and phosphatase inhibitor (Roche Applied 


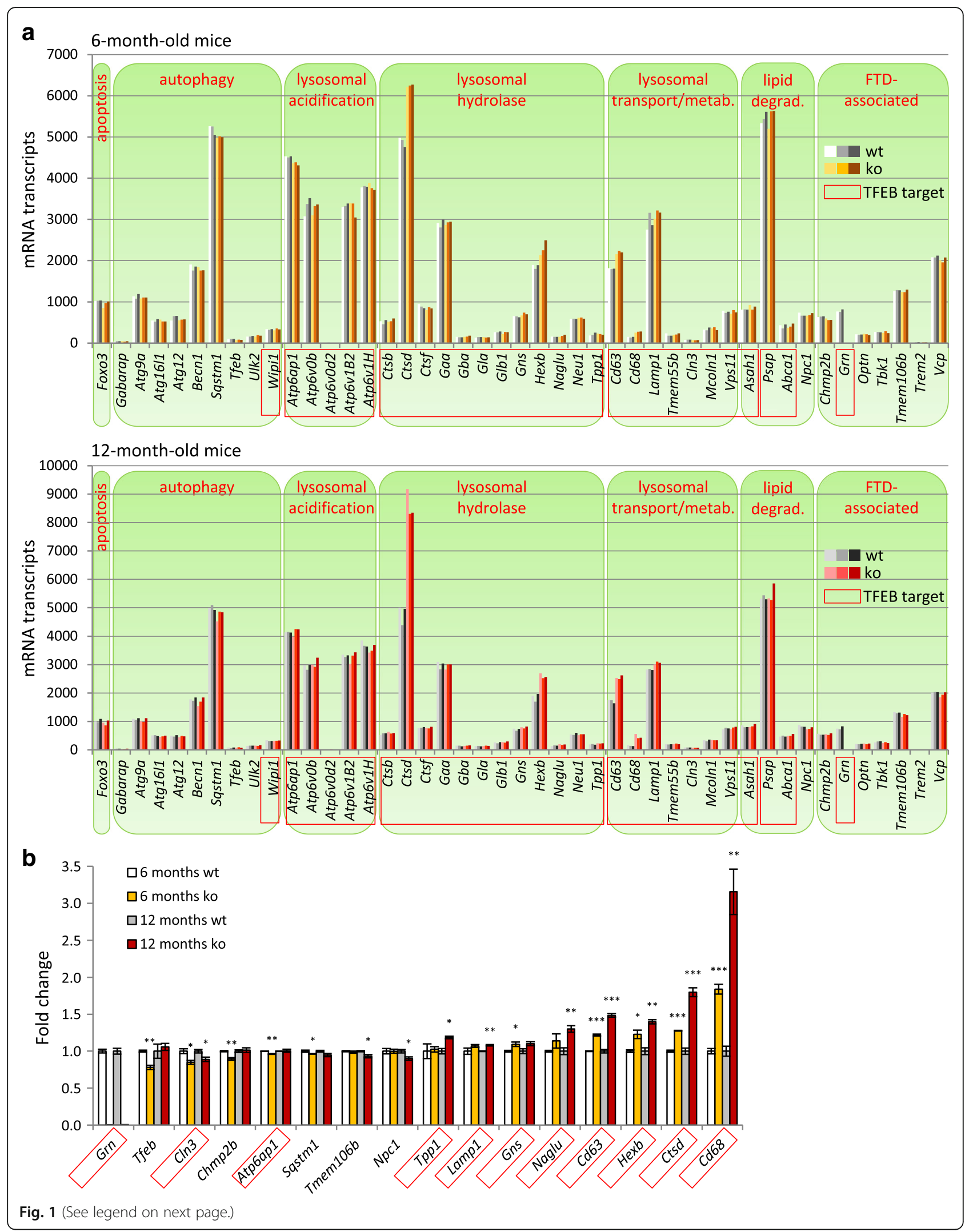


(See figure on previous page.)

Fig. 1 Minor alterations in expression of lysosomal and autophagy-related genes in brain of $\mathrm{Grn}^{-1-}$ mice. a mRNA expression for 45 selected genes associated with the lysosome-autophagy degradation pathway $[45,46]$ in brain of $\mathrm{Grn}^{+/+}$(wt) and $\mathrm{Grn}^{-/-}$(ko) mice at 6 and 12 months of age (for original data see Additional file 2). Genes are grouped by their function within these pathways or by their FTLD-association. Previously identified TFEB targets are labeled by red boxes [46, 47]. N=3 mice per group, notice the low expression differences between individual mice and between 6- and 12-month-old mice. Trem2 and Atp6rod2 were below the detection limit. b Fold change of gene expression which show at least one significand change either at 6 or 12 months of age. Data were normalized to the corresponding mean value of $\mathrm{Grn}^{+/+}$(wt) mice and are shown as mean $\pm \mathrm{SD}$. For statistical analysis the unpaired, two-tailed student's t-test was used $(n=3)\left(*^{*}, p<0.05 ;{ }^{*}, p<0.01 ; *^{* *}, p<0.001\right)$

Science) and centrifuged for $30 \mathrm{~min}, 15,000 \mathrm{x} \mathrm{g}, 4{ }^{\circ} \mathrm{C}$. The protein concentration of the supernatant was determined using the BCA protein assay (Pierce, Thermo Scientific) and equal amount of protein were separated by SDS-PAGE and transferred onto polyvinylidene difluoride membranes (Immobilon-P, Merck Millipore). For the detection of C-terminal fragments (CTF) of the amyloid precursor protein (APP) and saposin $\mathrm{D}$ the proteins were transferred onto nitrocellulose membranes (Protran BA85, GE Healthcare Lifesciences) and heated in PBS. Proteins of interest were detected by the indicated primary antibodies followed by horseradish peroxidase-conjugated secondary antibodies and ECL (Amersham Western Blotting Detection reagent, GE Healthcare Lifesciences) or ECL Plus (Pierce ECL Plus Western Blotting Substrates, Thermo Scientific). For the quantitatively analysis, images were taken by a Luminescent Image Analyzer LAS-4000 (Fujifilm Life Science, Tokyo, Japan) and evaluated with the Multi GaugeV3.0 software (Fujifilm Life Science, Tokyo, Japan).

\section{Cathepsin activity assay}

MEF cell pellets or aliquots of powdered mouse brain tissues were used for cathepsin D, B and L fluorescence based activity assays (Abnova). The samples were homogenized in the appropriate lysis buffer provided by the manufacturer and incubated for $10 \mathrm{~min}$ (MEF cell lysates) or $20 \mathrm{~min}$ (brain lysates) on ice, followed by a 5 min (MEF cell lysates) or 20 min (brain lysates) centrifugation at $15,000 \mathrm{x} \mathrm{g}, 4{ }^{\circ} \mathrm{C}$. The protein concentration was determined by BCA protein assay (Pierce, Thermo Scientific) and equal amounts of protein were used for the activity assays. The assays were performed in black 96-well plates (FluoroNunc) at $37{ }^{\circ} \mathrm{C}$ for $20 \mathrm{~min}$ according to the manufacturer's protocol. Cleavage of the quenched fluorescence substrate was continuously measured as increase of fluorescence signal by Fluoroskan Ascent FL plate reader (Labsystems). The relative enzyme activity was calculated for a period of time with linear substrate turnover.

\section{Metabolic labeling and protein turn over}

To analyze protein turnover, MEF at $70-80 \%$ of confluency were starved for $1 \mathrm{~h}$ in methionine-, cysteineand serum-free minimal essential medium (Invitrogen) and subsequently metabolically pulse-labeled with 18.5 MBq ${ }^{35} \mathrm{~S}$-methionine/cysteine (Met-S35-label, Hartmann Analytic) in methionine-, cysteine- and serum free medium for $1 \mathrm{~h}$, followed by indicated chase periods in the presence of a 5 -fold excess of unlabeled methionine. Cell lysates were prepared and labeled proteins were precipitated with $5 \%$ TCA for $1 \mathrm{~h}$ at $4{ }^{\circ} \mathrm{C}$, followed by $30 \mathrm{~min}$ centrifugation at $13,000 \mathrm{rpm}, 4{ }^{\circ} \mathrm{C}$. Pellets were washed twice with $80 \%$ acetone, dried at RT and resuspended in $50 \mu \mathrm{l}$ sample buffer. Remaining radioactive-labeled proteins were measure in triplicates in liquid scintillation counter (Tri-Carb 2810, Perkin Elmer).

\section{Statistical analysis}

For statistical analysis the unpaired, two-tailed student's t-test was performed when two groups of samples (wt and ko) were compared, for comparison of more than two groups, one-way ANOVA with Dunnett's post hoc test was used and statistical significance was set at *, $p<0.05 ;$ ***, $p<0.01$; ***, $p<0.001$; and ${ }^{* * * * *}, p<0.0001$.

\section{Results}

Subtle changes in lysosomal and autophagy-related gene expression in total brain of $\mathrm{Grn}^{-/-}$mice

Accumulating evidence indicates that PGRN plays a critical role for lysosomal integrity and function. To obtain insights into the role of PGRN in autophagic/lysosomal protein degradation pathways we performed on whole brain extract a NanoString based mRNA expression analysis of selected lysosomal and autophagy-related genes [45] (Fig. 1a). Surprisingly, expression of only very few genes was significantly altered in the brain of 6- and 12-month-old $\mathrm{Grn}^{-/-}$mice (Fig. 1a, b). Only eight genes, among which are three genes encoding the lysosomal membrane proteins Cd68, Cd63 and Lamp1, show a significantly elevated expression in $\mathrm{Grn}^{-/-}$mice. Additionally, the lysosomal hydrolases hexosaminidase subunit $\beta$ (Hexb) and cathepsin D (Ctsd) showed the strongest and age-dependent increase in $\mathrm{Grn}^{-/-}$mice (Fig. 1b). However, no general elevation of lysosomal and autophagy-related gene expression regulated by transcription factor EB (TFEB) $[46,50]$ was observed in $\mathrm{Grn}^{-/-}$mice brain. Thus, although $\mathrm{Grn}^{-1-}$ mice recapitulate important pathological features of NCL, expression of lysosomal genes is not overtly affected. 


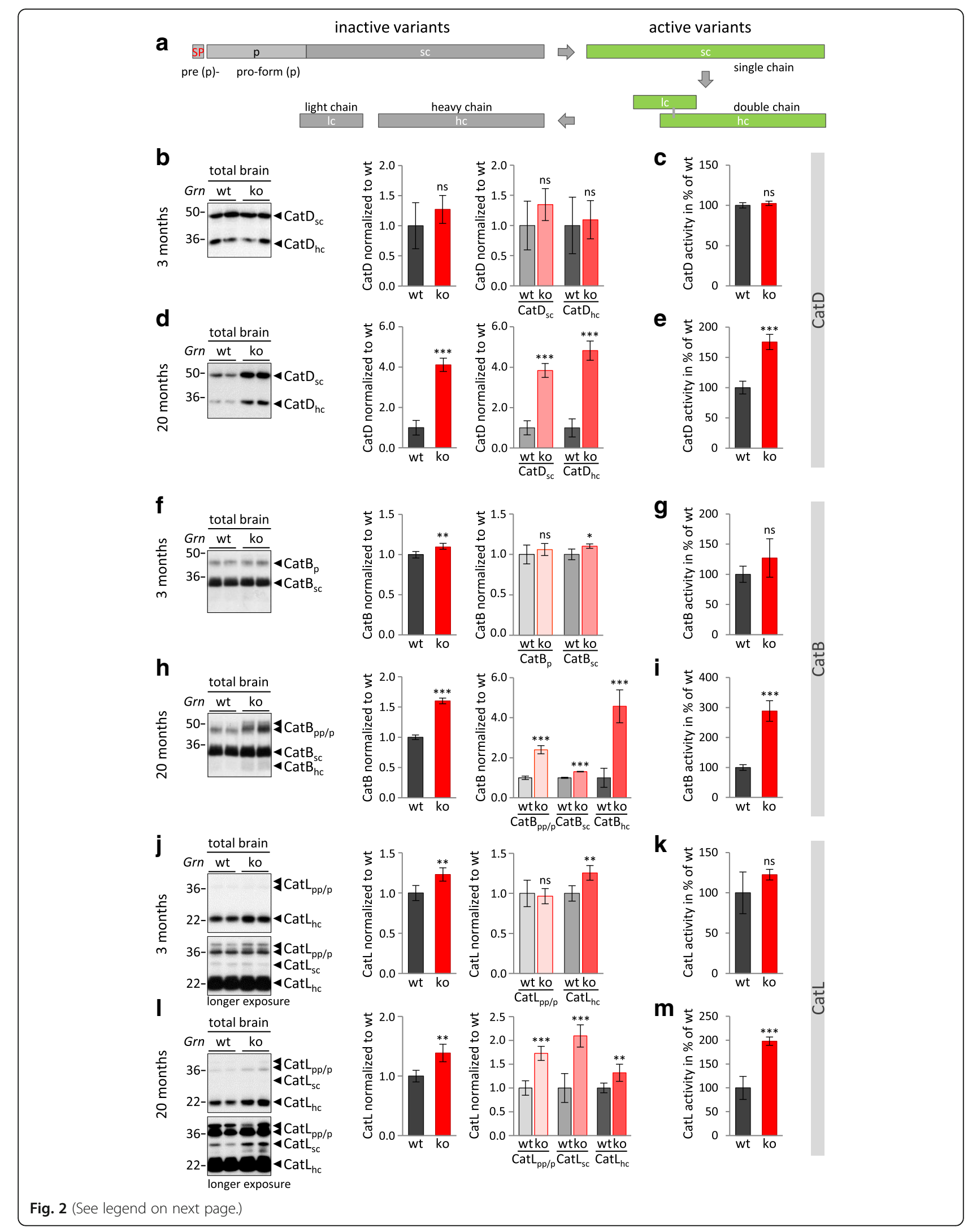




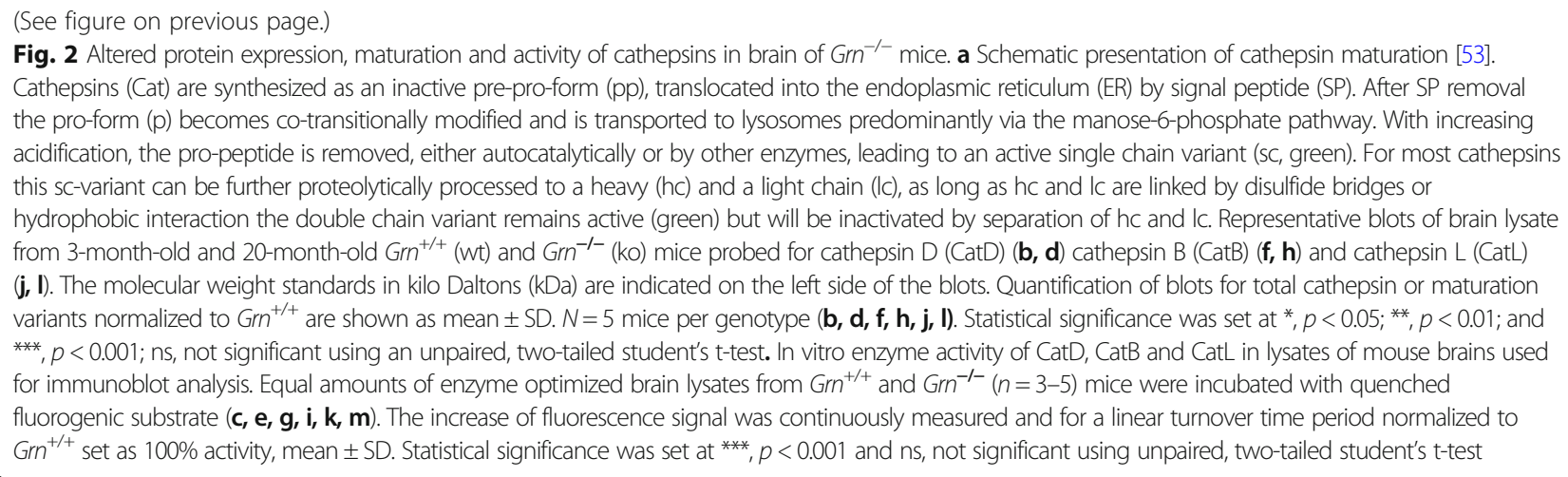

\section{Elevated cathepsin maturation and activity in PGRN deficient mouse brain}

We have previously shown that cathepsin D (CatD) is elevated in brain of young $\mathrm{Grn}^{-/-}$mice and that CatD accumulation further increases with age [18]. These findings have been confirmed [12,51], but the origin of CatD increase remains mainly unclear and cannot simply be explained as a compensation phenomenon in response to general reduced expression of lysosomal enzymes (Fig. 1). To address whether elevated Ctsd mRNA levels (Fig. 1b; Additional file 1: Figure S1) translate into increased protein levels and result in enhanced enzyme activity, we analyzed protein expression, maturation and in vitro activity of CatD in brain of 3- and 20-month-old mice (Fig. 2b-e). To further monitor lysosomal activity in $\mathrm{Grn}^{-l-}$ mice we also investigated protein expression, maturation and catalytic activity of two additional cathepsins, namely CatB (Fig. 2f-i) and CatL (Fig. 2j-m). Both lysosomal cysteine proteases have been associated with PGRN metabolism. CatL might be directly involved in lysosomal processing of PGRN into granulins [31] and CatL and CatB cleave and inactivate the secretory leucoprotease inhibitor (SLPI) which protects extracellular PGRN from processing [52]. Maturation and activation of most cathepsins follows a unified processing pathway generating active single and double chain variants (Fig. 2a) (reviewed in [53]). In 3-month-old $\mathrm{Grn}^{-/-}$mice, CatD expression, maturation and activity was unchanged (Fig. 2b, c; Additional file 1: Figure S1). In aged mice (20 months) active single chain CatD $\left(\mathrm{CatD}_{\mathrm{sc}}\right)$ as well as further processed heavy chain $\mathrm{CatD}\left(\mathrm{CatD}_{\mathrm{hc}}\right)$ are about 4 - to 5 -fold increased (Fig. $2 \mathrm{~d}$ ). This is accompanied by a 1.75 -fold elevated proteolytic activity in $\mathrm{Gr}^{-1-}$ mice brain (Fig. 2e). In contrast to the robust increase of the CatD protein levels, we could only detect a 2-fold increase of mRNA (Additional file 1: Figure S1) suggesting posttranscriptional regulatory mechanisms. CatB and CatL are slightly elevated in young $\mathrm{Grn}^{-/-}$ mice (Fig. 2f, j) but no significant change in their catalytic activity was observed (Fig. 2g, k). Their mRNA levels were not altered (CatB) or only slightly elevated (CatL)
(Additional file 1: Figure S1). In aged $\mathrm{Grn}^{-/-}$mice, CatB and CatL expression, processing and activity were elevated (Fig. 2h, i, l, m; Additional file 1: Figure S1). Thus, against the expectations that lysosomal activity might be decreased in $\mathrm{Grn}^{-/-}$mice, their proteolytic in vitro activity is elevated in total brain lysates.

\section{Increased activity of cathepsins in mouse embryonic fibroblasts (MEF) lacking PGRN}

MEF generated from $\mathrm{Grn}^{+/+}$show a robust localization of PGRN in lysosomes (Additional file 1: Figure S2a), while MEF generated from $\mathrm{Grn}^{-1-}$ littermates show an increase of LAMP1 and an accumulation of saposin D, which is in line with our previous observations in brains of $\mathrm{Grn}^{-1-}$ mice and FTLD/GRN patients [18] (Additional file 1: Figure S2b). We next examined the in vitro activity and maturation of CatD, CatB and CatL in $\mathrm{Grn}^{-/-}$ and $\mathrm{Grn}^{+/+} \mathrm{MEF}$ (Fig. 3). In $\mathrm{Grn}^{-/-}$MEF the overall CatD level was 1.7-fold elevated. Moreover, $\mathrm{Cat}_{\mathrm{hc}}$ was increased about eight fold whereas $\mathrm{CatD}_{\mathrm{sc}}$ expression was not altered (Fig. 3a). The elevated protein level of Cat $D_{h c}$ is in line with a significantly enhanced in vitro enzymatic activity (Fig. 3b). A second independent pool of MEF $\mathrm{Grn}^{-1-}$ as well as single cell clones additionally confirmed altered maturation and elevated levels of Cat $D_{h c}$ (Additional file 1: Figure S2c, d). Similar to mouse brain, CatB and CatL showed altered maturation (Fig. 3c, e) and a robust increase of in vitro activity (Fig. 3d, f). Low amounts of stably expressed PGRN were sufficient to rescue altered maturation of CatD and to lower hyperactivity of cathepsins (Fig. 3g, Additional file 1: Figure S3a, b). Thus, MEF, like total brain extract of $\mathrm{Grn}^{-/-}$mice, exhibit increased cathepsin expression, maturation and in vitro activity. To investigate the functional consequences of enhanced lysosomal activity we compared general protein degradation in $\mathrm{Grn}^{-/-}$and $\mathrm{Grn}^{+/+}$MEF. Newly synthesized proteins were metabolically pulse labeled for one hour and chased for indicated periods of time (Fig. 4a). The relative protein turnover calculated by the percentage of remaining radiolabeled protein was higher in $\mathrm{Gr}^{-/-}$MEF compared to 

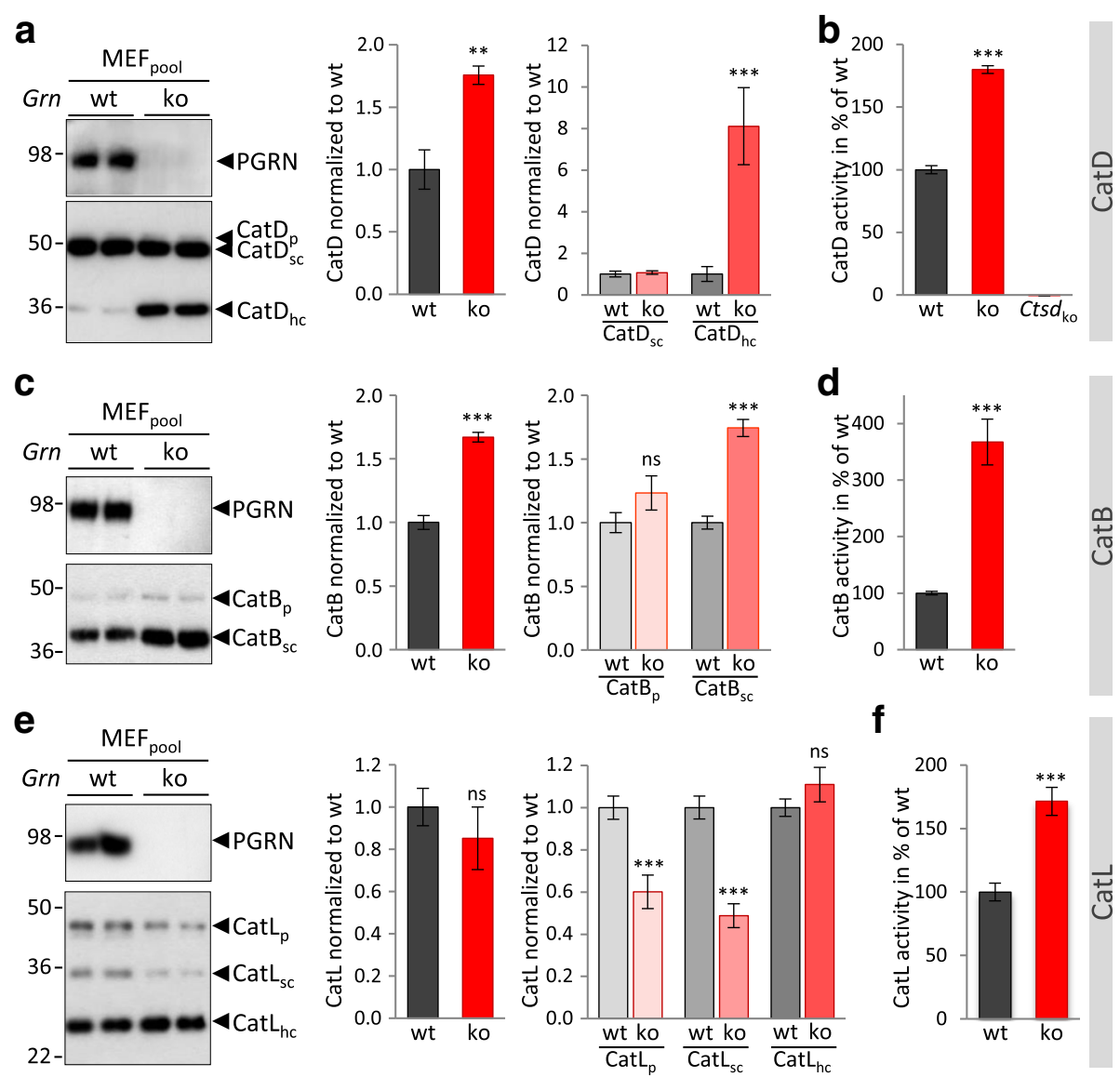

f
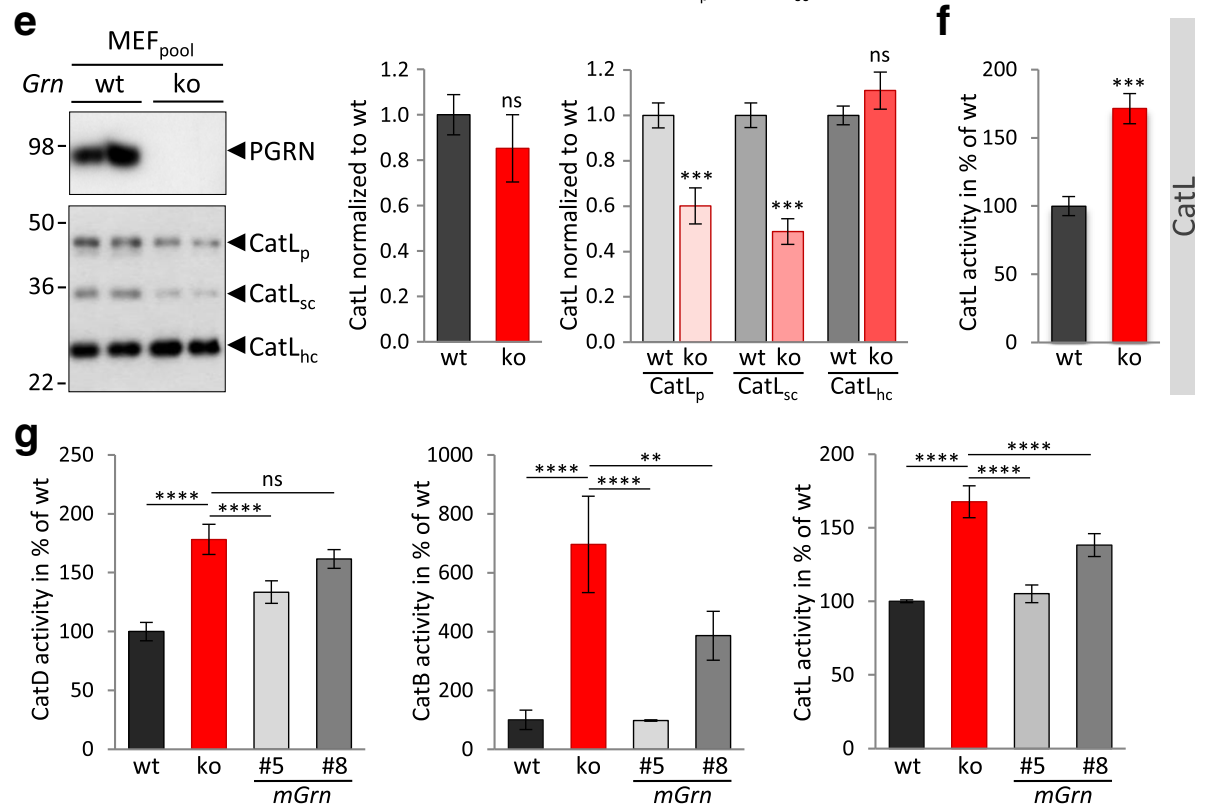

Fig. 3 PGRN loss alters maturation and elevates activity of cathepsins in MEF. a CatD expression and maturation in MEF pool $\mathrm{Grn}^{+/+}(\mathrm{wt})$ and $\mathrm{Grn}^{-/-}$(ko) shown in representative immunoblots. The pro-form $\mathrm{CatD}_{\mathrm{p},}$ single chain form $\mathrm{CatD}_{\mathrm{sc}}$ and heavy chain form $\mathrm{Cat}_{\mathrm{hc}}$ are indicated. Bar graphs show the quantification of blots for total CatD or maturation variants normalized to $\mathrm{Grn}^{+/+} \cdot \mathbf{b}$ CatD activity measured as cleavage of a quenched fluorogenic substrate. The increase of fluorescence signal was continuously measured and during a linear turnover time period normalized to $\mathrm{Grn}^{+/+}$. Note that extracts of CatD deficient MEF ( $C t s d_{\mathrm{ko}}$ ) show no CatD activity and therefore confirm the specificity of the assay. c CatB expression and maturation in MEF pool $\mathrm{Grn}^{+/+}$ (wt) and $\mathrm{Grn}^{-1-}$ (ko) shown in representative immunoblots. The pro-form $\mathrm{CatB}_{\mathrm{p},}$ single chain form $\mathrm{CatB}_{\mathrm{sc}}$ are indicated. Bar graphs show the quantification of blots for total CatB or maturation variants normalized to $\mathrm{Grn}^{+/+}$. $\mathbf{d}$ CatB activity normalized to $\mathrm{Grn}^{+/+}$. e CatL expression and maturation in $\mathrm{MEF}_{\text {pool }} \mathrm{Grn}^{+/+}$ (wt) and $\mathrm{Grn}^{-1-}(\mathrm{ko})$ shown in representative immunoblots. The pro-form CatL , single chain form Cat $\mathrm{L}_{\text {sc }}$ heavy chain form Cat $\mathrm{L}_{\mathrm{hc}}$ are indicated. Bar graphs show the quantification of blots for total CatL or maturation variants normalized to $\mathrm{Grn}^{+/+}$. $\mathbf{f}$ CatL activity normalized to $\mathrm{Grn}^{+/+}$. $\mathbf{g}$ PGRN deficient MEF were stably transfected with mouse PGRN (mGrn) and low PGRN expressing single cell clones (\#5, \#8) were analyzed for CatD, CatB and CatL in vitro activity. Notice that very low expression of PGRN (\#8) lowers cathepsin activities and thereby partially rescues the phenotype of the $\mathrm{Gr}^{-1-} \mathrm{MEF}$, while the higher expressing clone (\#5) allows a full rescue for CatB and CatL. The molecular weight standards in kilo Daltons $(\mathrm{kDa})$ are indicated on the left side of the blots. All bar graphs are shown as mean \pm SD. Statistical significance was set at ${ }^{*}, p<0.05 ;{ }^{*}, p<0.01 ;{ }^{* *}, p<0.001$; and ${ }^{* * * *}, p<0.0001$ with ns as not significant using a-f unpaired, two-tailed student's t-test $(n=3)$, $\mathbf{g}$ one-way ANOVA with Dunnett's post hoc test $(n=3-6)$

$\mathrm{Grn}^{+/+}$MEF (Fig. 4a). In particular, during the first $24 \mathrm{~h}$ protein degradation is elevated in $\mathrm{Grn}^{-/-} \mathrm{MEF}$ (Fig. 4a). Elevated lysosomal protein turnover in PGRN deficient MEF was also indicated by lower steady state levels of proteins degraded by lysosomes such as APP and its CTF [54-57] (Fig. 4b), while the App mRNA level is not altered in $\mathrm{Grn}^{-1}$ 


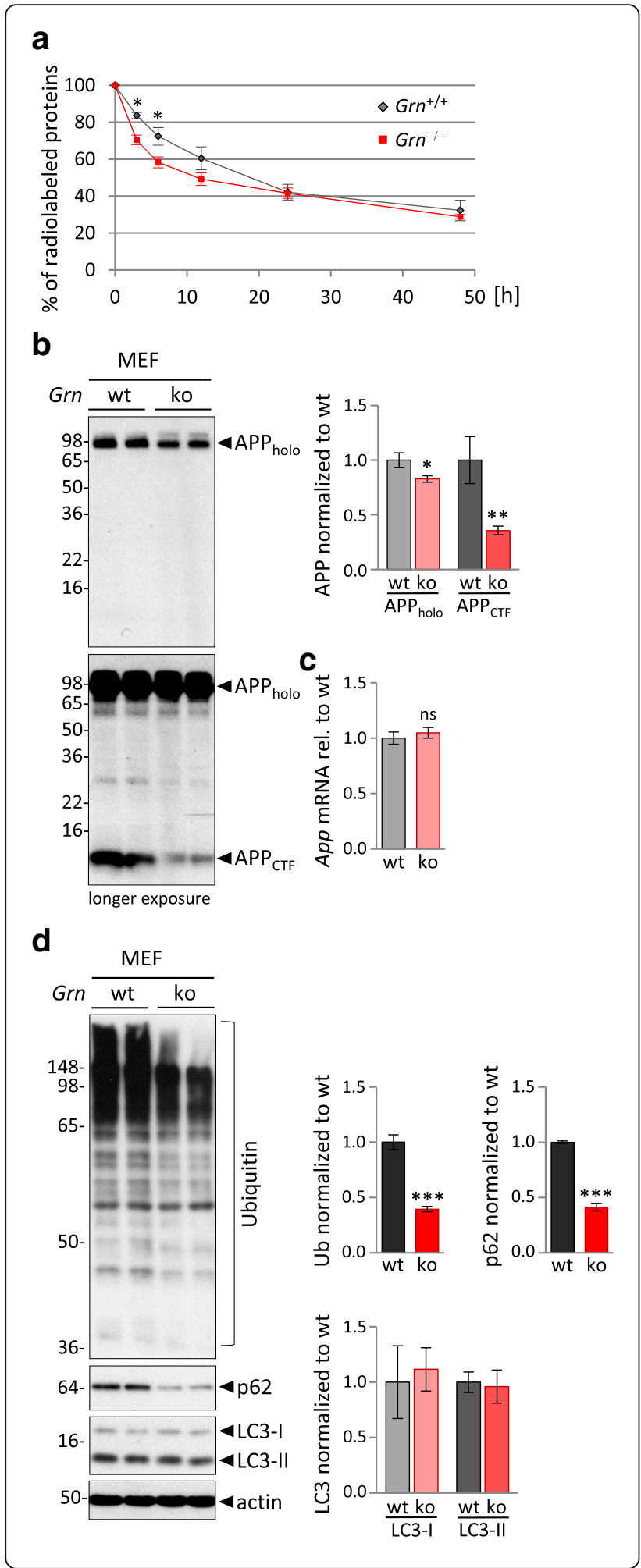

Fig. 4 Elevated lysosomal activity results in enhanced fast protein degradation in $\mathrm{Gr}^{-1-} \mathrm{MEF}$. a Turnover of ${ }^{35} \mathrm{~S}$-methionine radiolabeled proteins. MEF at 70-80\% confluency were metabolically pulse-labeled with ${ }^{35} \mathrm{~S}$-methionine/cysteine for $1 \mathrm{~h}$, followed by indicated chase periods. Radioactivity of ${ }^{35} \mathrm{~S}$ - labeled proteins at chase time point $0 \mathrm{~h}$ was set to $100 \%$ and remaining radioactive-labeled proteins at later chase points were normalized to the initial radioactivity at time point $0 \mathrm{~h}$. For statistical analysis the unpaired, two-tailed student's t-test was used to compare $\mathrm{Gr}^{-1-}$ to Grn ${ }^{+/+}$MEF $(n=5),(*, p<0.05)$. b APP holoprotein (APP holo $)$ and C-terminal fragments ( $\mathrm{APP}_{\mathrm{CTF}}$ ) detected by immunoblotting of $\mathrm{MEF}_{\text {pool }}$ $\mathrm{Grn}^{+/+}(\mathrm{wt})$ and $\mathrm{Grn}^{-/-}$(ko) lysates. The molecular weight standards in kilo Daltons $(\mathrm{kDa})$ are indicated on the left side of the blots. Bar graphs show the quantification of the blots for APP holo and APP (TF normalized to $\mathrm{Grn}^{+/+}$ $(w t)$ as mean \pm SD. c Quantification of App mRNA of MEF pool $\mathrm{Grn}^{-/-}(\mathrm{ko})$ normalized to $\mathrm{Grn}^{+/+}$(wt) as mean \pm SD. d Ubiquitin (Ub), p62, LC3-I and LC3-II detected by immunoblotting of $\mathrm{MEF}_{\text {pool }} \mathrm{Grn}^{+/+}$(wt) and $\mathrm{Grn}^{-/-}$(ko) lysates. Bar graphs show the quantification of the blots normalized to wt as mean \pm SD. $\mathbf{b}$-d For statistical analysis the unpaired, two-tailed student's ttest was used to compare ko to wt cells $(n=3)\left({ }^{*}, p<0.05 ;{ }^{* *}, p<0.01 ;{ }^{* * *}\right.$, $p<0.001$; ns, not significant)

MEF (Fig. 4c). To address the question whether autophagy is altered by PGRN deficiency, we analyzed ubiquitin and the adapter protein p62/SQSTM1 levels in $\mathrm{Grn}^{-1-} \mathrm{MEF}$. Interestingly, we detect reduced levels of ubiquitinated proteins and p62 in $\mathrm{Grn}^{-/-}$MEF compared to $\mathrm{Grn}^{+/+}$MEF but no change in autophagy marker LC3I and LC3II (Fig. 4d). Thus, we do not find evidence that enhanced autophagosome formation contributes to the enhanced lysosomal degradation in $\mathrm{Grn}^{-1-}$ MEF (Fig. 4a). Having observed an increased activity of cathepsins as well as enhanced lysosomal protein degradation in $\mathrm{Grn}^{-1-}$ MEF, we asked whether PGRN or the proteolytically generated granulin peptides are direct inhibitors of lysosomal cathepsins. To do so, recombinant PGRN, granulin peptides generated by elastase digestion of PGRN or recombinant granulin E were added to in vitro cathepsin activity assays using lysates derived from $\mathrm{Grn}^{-1-}$ MEF (Additional file 1: Figure S4). None of the PGRN variants added to the in vitro assays had a significant effect on proteolytic activity suggesting that cathepsins may not be directly inhibited by an interaction with PGRN or the granulin peptides.

\section{Selective impairment of lysosomal processing of} cathepsins in microglia upon PGRN deficiency

Enhanced lysosomal activity of cathepsins in $\mathrm{Grn}^{-1-}$ MEF and total brain homogenates of $\mathrm{Grn}^{-/-}$mice is contradictory to impaired protein degradation and accumulation of lipofuscin and NCL storage components caused by PGRN deficiency. Therefore, we analyzed the consequence of PGRN deficiency in microglia, which are known to express more than 50-fold higher levels of Grn mRNA as compared to neurons $[58,59]$. We hypothesized that PGRN depletion may cause cell autonomous 
a

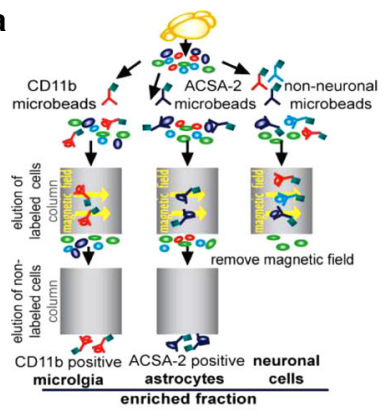

c

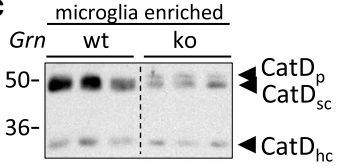

d

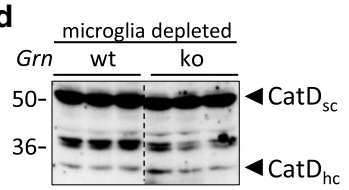

e

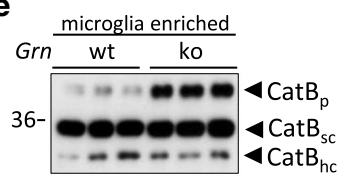

f

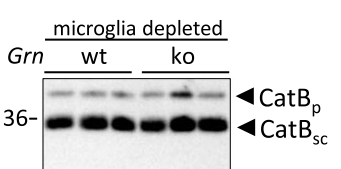

g

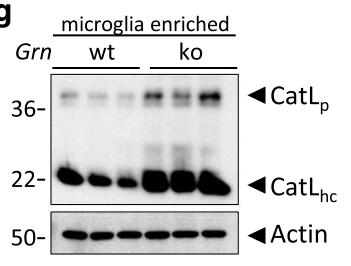

h microglia depleted

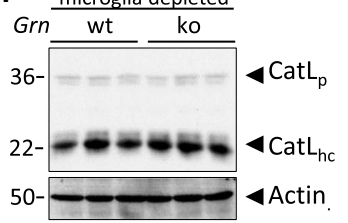

i microglia enriched

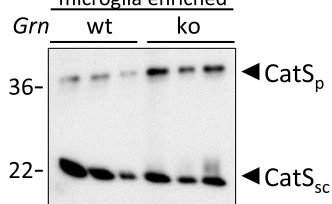

b

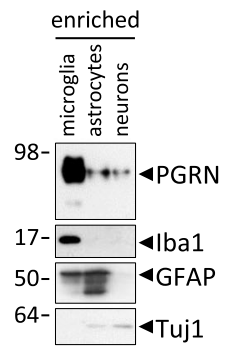

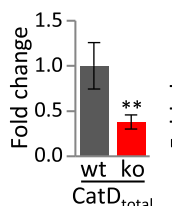

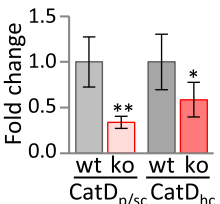

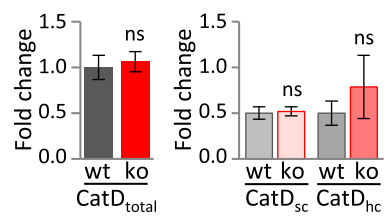

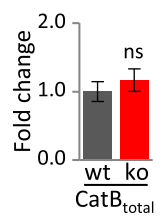

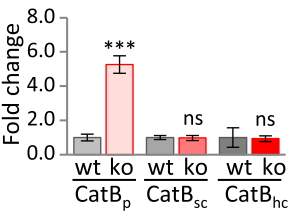

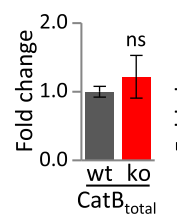

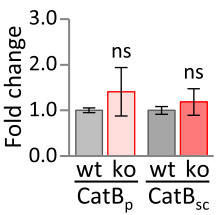

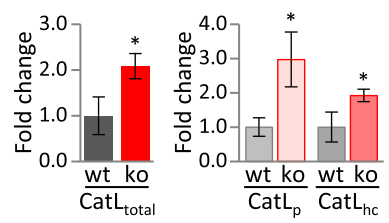

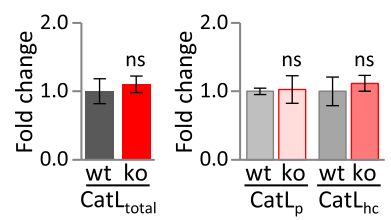

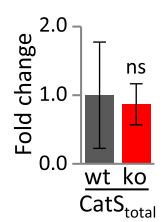

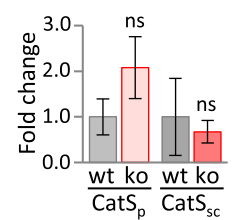

Fig. 5 (See legend on next page.) 
(See figure on previous page.)

Fig. 5 Cathepsin maturation is selectively impaired in $\mathrm{Grn}^{-1-}$ microglia. a Schematic representation of the brain cell isolation using MACS Technology (Miltenyi Biotec) b PGRN expression in acutely isolated microglia, astrocytes and neurons enriched fractions of 4- month-old wt mice detected by immunoblotting. The identity of neural cell types was verified by detection of Ibal for microglia, GFAP for astrocytes and Tuj 1 for neurons. c-i Cathepsin expression and maturation in the CD11b-positive, microglia enriched, fraction and the CD11b-negative, microglia depleted cellular fraction isolated form cortices of brain from 3-month-old $\mathrm{Grn}^{+/+}$(wt) and $\mathrm{Grn}^{-/-}$(ko) mice. Representative immunoblots for the cathepsin expression of CatD (c, d), CatB (e, f), CatL $(\mathbf{g}, \mathbf{h})$ and for CatS (i) (only microglia enriched fraction). The molecular weight standards in kilo Daltons $(\mathrm{kDa})$ are indicated on the left side of all immunoblots. A dotted line in the blot indicates that samples of heterozygous mice were cut out, but all samples were loaded on one gel. Quantification of immunoblots for total cathepsin or maturation variants pro-form (p), single chain (sc) and heavy chain (hc) normalized to wt are shown as mean \pm SD. For statistical analysis the unpaired, two-tailed student's t-test was used to compare ko to wt mice $(n=3-5)\left({ }^{*}, p<0.05 ;{ }^{* *}, p<0.01 ;{ }^{* *}, p<0.001 ; n s\right.$, not significant) (c-i)

effects in microglia, which could be different to the majority of the non-microglial brain cell population. First, to confirm predominant PGRN protein expression in microglia, we performed immunoblots on lysates of acutely isolated microglia, astrocytes and neurons from adult wildtype mouse brain (Fig. 5a). This fully confirmed that PGRN is most robustly expressed in microglia (Fig. 5b). To address whether PGRN deficiency results in cell autonomous alterations of lysosomal function in microglia, we analyzed protein expression and maturation of selected cathepsins in acutely isolated microglia. Strikingly, microglia isolated from 3-month-old $\mathrm{Grn}^{-/-}$ mice show impaired maturation of cathepsins and an accumulation of inactive pro-forms of CatD, CatB, CatL and CatS (Fig. 5c, e, g, i). For CatB and CatL, the pro-form is significantly elevated (Fig. 5e, g). The relative increase of

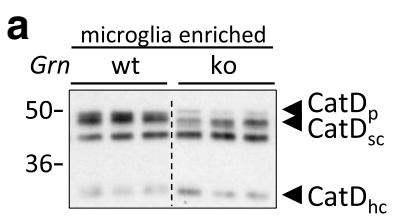

b
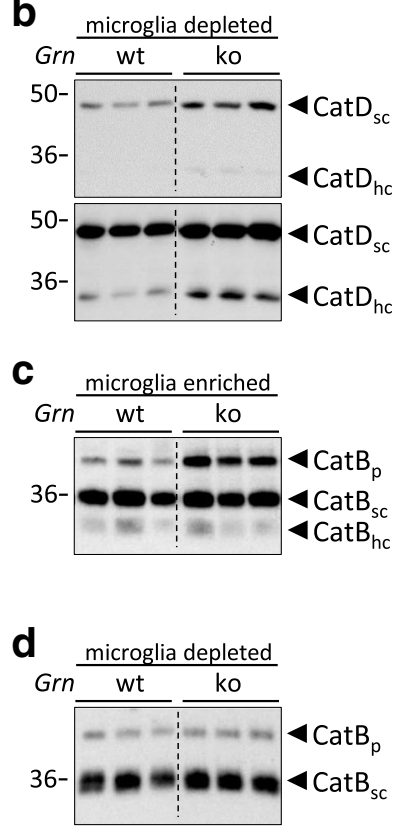
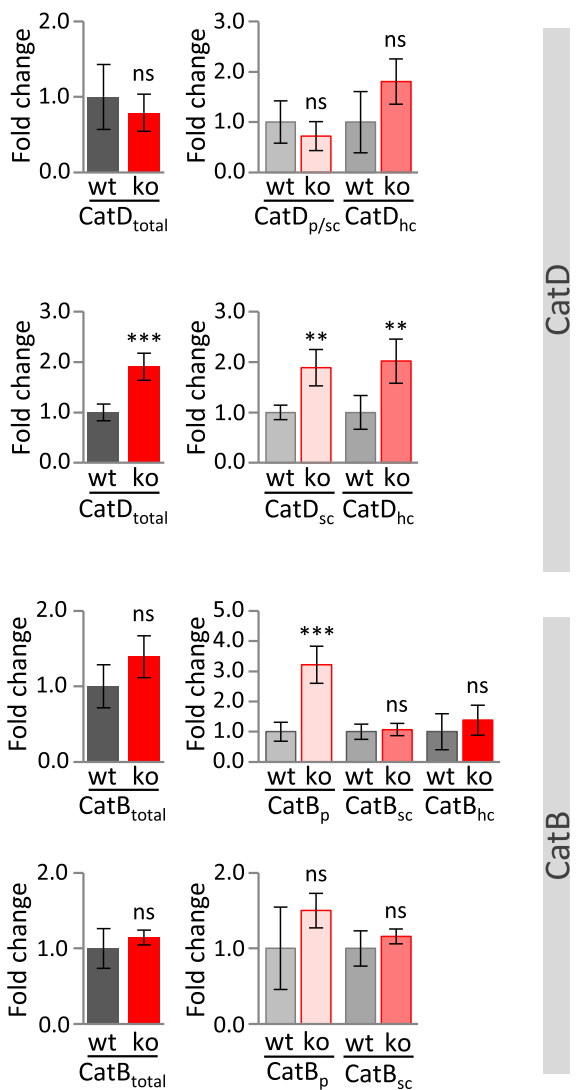

Fig. 6 Cathepsins are elevated in the microglia depleted cell fraction of aged $\mathrm{Grn}^{-/-}$mice. a-d Cathepsin expression and maturation in the CD1 1b-positive, microglia enriched, fraction and the CD11b-negative, microglia depleted cellular fraction isolated form cortices of brains from 12-month-old Grn ${ }^{+/+}$(wt) and $\mathrm{Grn}^{-1-}(\mathrm{ko})$ mice. Representative immunoblots for the expression of CatD $(\mathbf{a}, \mathbf{b})$, CatB $(\mathbf{c}, \mathbf{d})$. The molecular weight standards in kilo Daltons (kDa) are indicated on the left side of all immunoblots. A dotted line in the blot indicates that samples of heterozygous mice were cut out, but all samples were loaded on one gel. Quantification of immunoblots for total cathepsin or pro-form (p), single chain (sc) and heavy chain (hc) normalized to wt are shown as mean \pm SD. For statistical analysis the unpaired, two-tailed student's t-test was used to compare ko to wt mice $(n=3-5)\left({ }^{*}, p<0.05 ; * *, p<0.01 ; * *, p<0.001 ; n s\right.$, not significant) (a-d) 
CatD $\mathrm{p}_{\mathrm{p}}$ in $\mathrm{Grn}^{-/-}$could not be quantified since $\mathrm{CatD}_{\mathrm{p}}$ cannot be detected in $\mathrm{Grn}^{+/+}$microglia. Despite a general increase of pro-cathepsins, the levels of mature cathepsins are differentially affected by the loss of PGRN. Thus, the total protein level of CatD and the potentially active forms Cat $D_{\mathrm{sc}}$ and $\mathrm{Cat}_{\mathrm{hc}}$ are significantly reduced in microglia of $\mathrm{Grn}^{-/-}$(Fig. 5c). However a significantly reduced in vitro activity of CatD could not be detected (Additional file 1: Figure S5a). For the other analyzed cathepsins the total level is unchanged (CatB, CatS) (Fig. 5e, i) or even elevated (CatL) (Fig. 5g). In the microglia depleted fraction isolated from 3-month-old mice, no significant differences of cathepsin maturation, expression level or activity between $\mathrm{Grn}^{-1-}$ and $\mathrm{Grn}^{+/+}$can be observed (Fig. 5d, f, h; Additional file 1: Figure S5a), whereas in the microglia depleted fraction of 12-month-old mice CatD is significantly elevated in $\mathrm{Grn}^{-/-}$ (Fig. 6b) which results in enhanced CatD activity (Additional file 1: Figure S5b). However, in microglia of 12-month-old $\mathrm{Grn}^{-1-}$ mice altered expression levels of CatD and CatB are not further enhanced but rather slightly reduced (Fig. 6a, c), e.g. immature $\mathrm{Cat}_{\mathrm{p}}$ shifts from an almost 6-fold increase in 3-month-old mice to an 3-fold increase in 12-month-old mice (Fig. 6c). In line with altered processed or reduced lysosomal cathepsins specifically in microglia, LAMP1 and saposin D accumulation occurred exclusively (LAMP1) or more robust (saposin D) in the microglia enriched fraction compared to the microglia depleted fraction isolated from 3-month-old mice (Fig. 7a-c).

Thus our data indicate that microglia and the remaining neural cell populations show fundamentally different lysosomal phenotypes upon PGRN deficiency.

\section{Discussion}

Accumulating evidence suggests that impaired lysosomal protein degradation plays a major role in FTLD-TDP [15]. Lysosomal dysfunction seems to be specifically associated with FTLD-TDP caused by GRN haploinsufficiency [18]. Furthermore total loss of PGRN leads to NCL (CLN11) [3], a lysosomal storage disease with severe neurodegeneration. However, it is still unknown if and how PGRN affects lysosomal homeostasis. Based on the selective expression of GRN in microglia (Fig. 5b) $[51,58,59]$, we now searched for cell autonomous and non-cell autonomous deficits upon loss of PGRN.

We provide strong evidence that loss of PGRN selectively impairs lysosomal function in microglia. Microglia isolated from 3-month-old $\mathrm{Grn}^{-1-}$ mice showed strongly reduced CatD levels compared to microglia isolated from $\mathrm{Grn}^{+/+}$mice, which surprisingly did not result in a significantly reduced in vitro activity. However, impaired maturation might not be reflected by the in vitro activity assay since defective CatD maturation and catalytic activity could be hidden by optimal in vitro conditions. In addition, maturation of CatB, CatL and CatS was

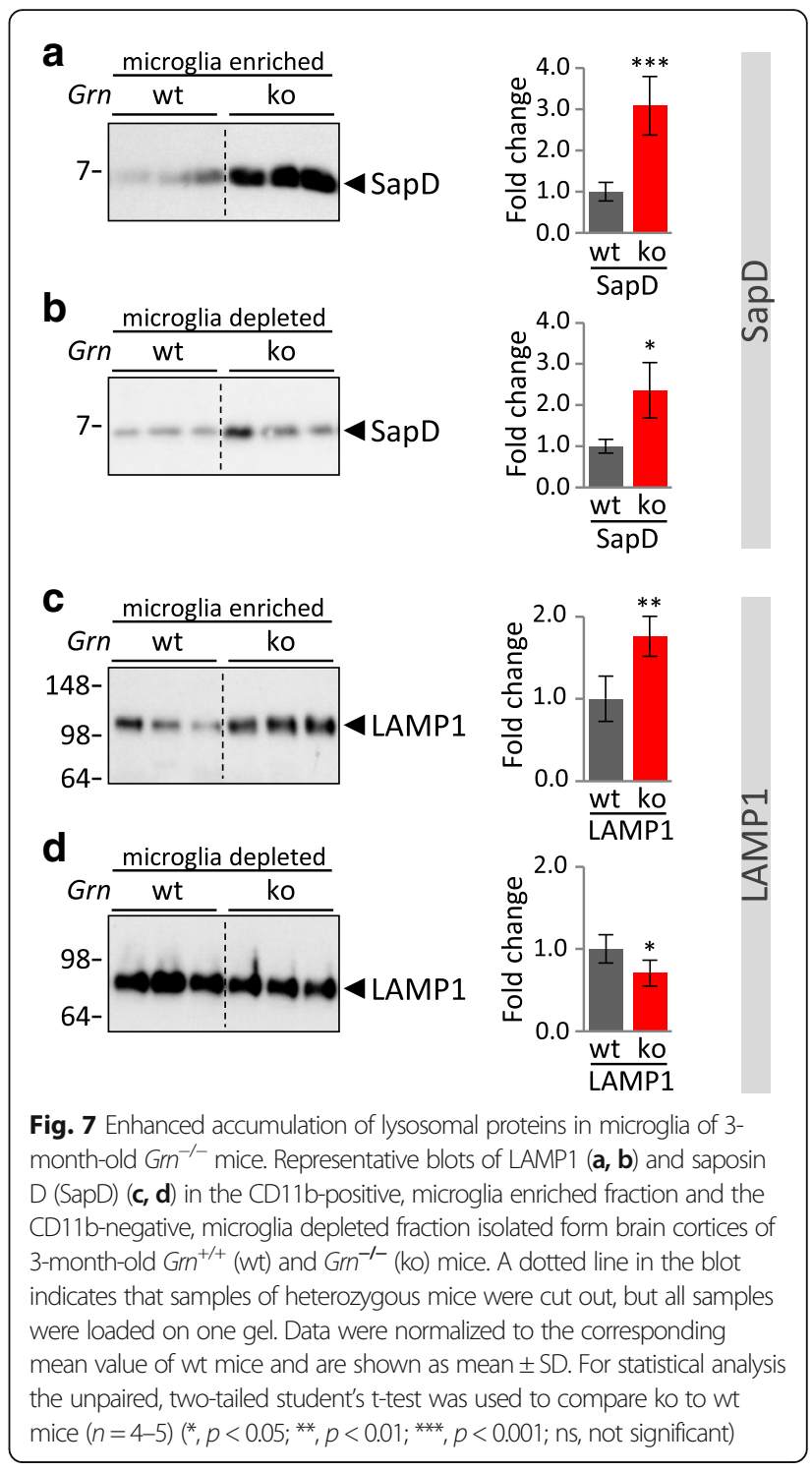

impaired. In contrast, in the microglia depleted fraction, isolated from the same 3-month-old $\mathrm{Grn}^{-1-}$ mice, no altered cathepsin expression or maturation was observed. Furthermore, during ageing saposin D and LAMP1 accumulated earlier and to a higher extent in the microglia enriched fraction than in the microglia depleted fraction. Our finding that impaired maturation of lysosomal enzymes in microglia already occurs in early adulthood before other pathological hallmarks suggests that lysosomal dysfunction may be a primary consequence upon loss of PGRN expression. Thus, our findings suggest a cell autonomous reduction of lysosomal function caused by PGRN deficiency in microglia, which as a consequence appears to culminate during ageing in a compensatory upregulation of lysosomal activity selectively in non-microglial cells. Indeed, in the microglia depleted fraction isolated from aged $\mathrm{Grn}^{-/-}$mice CatD single and 
heavy chain are 2 -fold and CatD in vitro activity is 2.5-fold elevated compared to $\mathrm{Grn}^{+/+}$mice. Our findings are supported by the observation that cultured neurons from $\mathrm{Grn}^{-/-}$mice show enhanced lysosomal proteolysis [51]. Moreover, in brain tissue of FTLD-TDP patients CatD is accumulating in neurons [21]. In line with enhanced cathepsin expression in non-microglial cells, mRNA, protein levels and in vitro activities of CatD, CatB, and CatL were increased in total brain of aged $\mathrm{Grn}^{-1-}$ mice. Furthermore, in line with recent findings $[21,38,40,51,59,60]$, a subset of lysosomal proteases and membrane proteins were upregulated in 6- and 12-month-old $\mathrm{Grn}^{-1-}$ mice. In addition to altered cathepsin levels, we demonstrate altered proteolytic processing and maturation of CatD, CatB, and CatL in the microglia enriched fraction, total brain lysates and MEF of $\mathrm{Grn}^{-/-}$mice. While in microglia proteolytic inactive pro-forms accumulate, potentially active single chain or heavy chain variants accumulate in total brain and MEF in accordance with increased in vitro activity. For example, robustly enhanced levels of the Cat $D_{h c}$ variant are observed in $\mathrm{Grn}^{-1-}$ MEF which is in line with findings by Tanaka et al. [21]. Previous research revealed enhanced [51, 59] as well reduced lysosomal enzyme activities $[38,39]$ in various $\mathrm{Grn}^{-1-}$ cells types or tissue.
Based on our findings, these discrepancies may be explained by different cell types analyzed, difficulties with the determination of specific activities of lysosomal enzymes due to their complex proteolytic processing and consequences for their proteolytic activity [53, 61]. Single chain variants as well as dimeric variants of heavy and light chain are catalytically active whereas separated heavy and light chains are inactive [53, 61]. Since we cannot determine the amount of active species, we cannot calculate the specific activity. Indeed, in total brain of $\mathrm{Grn}^{-1-}$ mice the increase of CatD protein is much stronger than the increase in enzyme activity which might indicate reduced specific activity as previously shown for CatD [38, 39]. However, it is unlikely that PGRN directly affects the specific activity of lysosomal proteases, because in our hands, adding PGRN, elastase digested PGRN, or granulin $\mathrm{E}$ to the in vitro activity assays of CatD, CatB, and CatL did not alter their activity. This might indicate that PGRN most likely modulates maturation and turnover of cathepsins.

In MEF, enhanced cathepsin activities are reversible by low expression levels of PGRN. Rescue of the lysosomal phenotype of $\mathrm{Grn}^{-/-}$by a very minor amount of PGRN is in line with recent data showing that low levels of AAV-expressed neuronal PGRN are sufficient to rescue

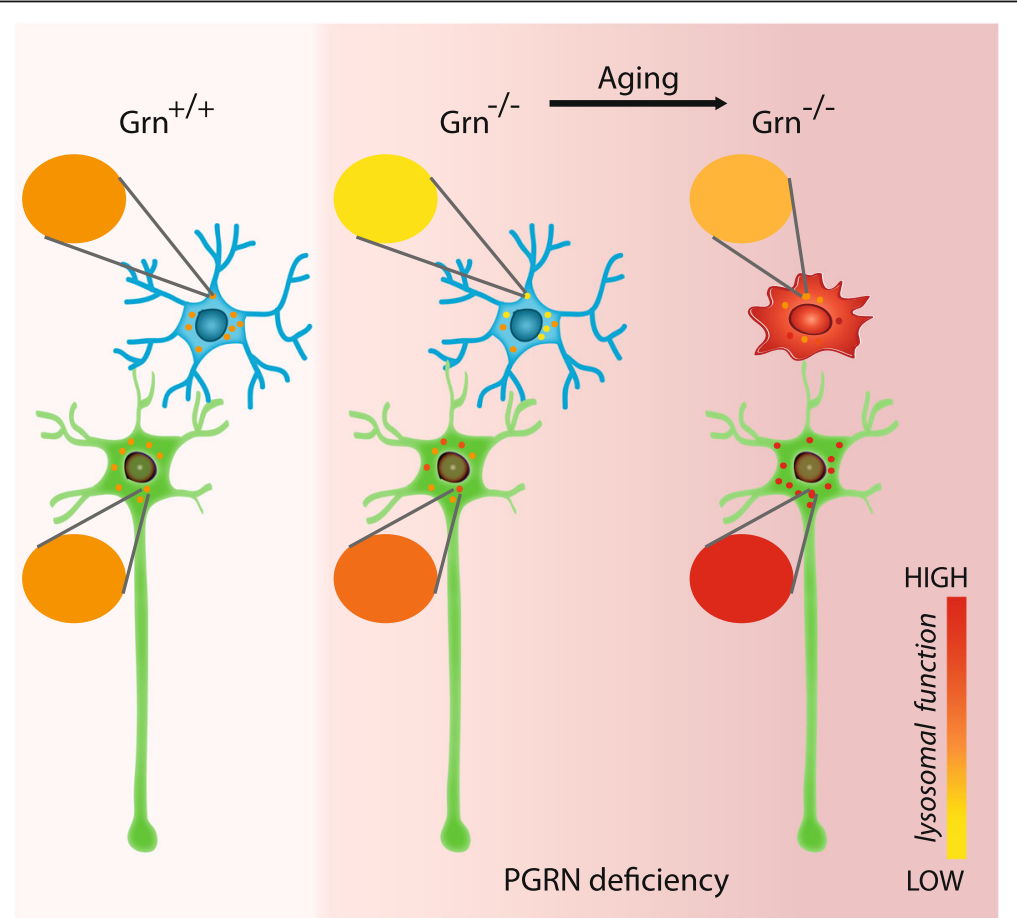

Fig. 8 Schematic summary of differential effects of PGRN deficiency on brain cell types. Lysosomal impairment in microglia observed in young $\mathrm{Grn}^{-1-}$ mice result in enhanced lysosomal activity in non-microglial brain cells like neurons in aged $\mathrm{Grn}^{-1-}$ mice. Basal lysosomal functions of microglia and neurons are indicated in orange, changes to lower activity (yellow) in microglia or higher activity (red) in neurons or other nonmicroglial brain cells are caused by PGRN deficiency and aging 
lysosomal phenotypes of Grn knockout mice [62]. Moreover, this also provides additional support for the lack of lysosomal abnormalities in heterozygous, neuronal or incomplete microglial Grn knockout mouse models [63, 64]. Finally, elevated catalytic activities of cathepsins result in enhanced protein turnover in $\mathrm{Gr}^{-1-}$ MEF, which indicates enhanced protein degradation in lysosomes. In line with enhanced lysosomal degradation, levels of lysosomal targeted proteins such as mature APP and its CTF are significantly reduced in $\mathrm{Grn}^{-/-}$MEF while LC3I and LC3II levels are unchanged. Only under cellular stress impaired autophagy or altered autophagic flux has been reported for bone marrow derived macrophages (BMDM) [40].

The cell type dependent effects of PGRN deficiency in microglial and non-microglial cells could be caused by different lysosomal gene expression signatures in microglia/monocytes compared to other brain cells. Microglia not only express more and higher levels of lysosomal enzymes, they also express more and higher levels of lysosomal enzyme inhibitors. Thus regulation of lysosomal activity might be more complex in microglia. Further work needs to be done to elucidate how PGRN modulates cathepsin activities and which role lysosomal generated granulins play [31,32]. With this work we provide strong evidence that PGRN plays a role as modulator of lysosomal activity by affecting maturation of lysosomal cathepsins. Such a function has been suggested for granulin-like domains located at the C-terminus of papain-like cysteine protease in plants [65-67]. Here, the granulin domain might slow maturation of the protease. Furthermore, the granulin domain must be proteolytically removed to allow full maturation $[68,69]$.

Finally, the divergent effects of PGRN deficiency in microglial and non-microglial cells not only provide evidence for differential cell autonomous and non-autonomous activities of PGRN, but also suggest a crosstalk of microglia with other cell types throughout the brain. Interestingly, we [70] and others [71] previously found that microglial loss-of-function mutations in TREM2 affect energy metabolism throughout the entire brain. Again, a rather small percentage of brain cells seemed to influence metabolism throughout the entire brain.

\section{Conclusions}

We conclude that PGRN deficiency leads to cell autonomous altered maturation and turnover of lysosomal cathepsins with cell type dependent differences and consequences. In particular in microglia, PGRN deficiency results in accumulation of inactive cathepsin pro-forms, while in other brain cells and in MEF, variants with increased catalytic activities were found. We speculate that impaired lysosomal function in microglia caused by PGRN deficiency already in young adults is likely responsible for impaired protein degradation and lipofuscin accumulation. With aging of $\mathrm{Grn}^{-/-}$mice, non-microglial brain cells try to compensate decreased protein degradation by microglia, with enhanced expression of selective cathepsins as shown for CatD, CatB and CatL (Fig. 8).

\section{Additional files}

\begin{abstract}
Additional file 1: Figure S1. Elevated transcript levels of cathepsins in aged $\mathrm{Grn}^{-1-}$ mice. Figure S2. PGRN loss results in accumulation of LAMP1 and saposin D in MEF. Figure S3. Altered maturation of CatD and activity of cathepsins can be rescued by stable PGRN expression. Figure S4. PGRN, elastase digested PGRN and granulin $E$ do not affect in vitro activity of cathepsins. Figure S5. Selectively enhanced CatD in vitro activity in non-microglial brain cells of aged $\mathrm{Grn}^{-1-}$ mice. (PPTX $1753 \mathrm{~kb}$ )
\end{abstract}

Additional file 2: Table S1. mRNA expression of selected genes associated with the lysosome-autophagy degradation pathway in brain of Grn+/+ and Grn-/- mice at 6 and 12 months of age. (XLSX $30 \mathrm{~kb}$ )

\section{Abbreviations}

APP: Amyloid precursor protein; BMDM: Marrow derived macrophages; CatB: Cathepsin B protein; CatD: Cathepsin D protein; CatL: Cathepsin L protein; CatS: Cathepsin S protein; CNS: Central nervous system; CTF: Cterminal fragment; Ctsb: Mouse cathepsin B gene; Ctsd: Mouse cathepsin D gene; Ctsl: Mouse cathepsin L gene; FTLD: Frontotemporal lobar degeneration; GRN: Human progranulin gene; Grn: Mouse progranulin gene; hc: Heavy chain; Hexb: Hexosaminidase subunit b; MEF: Mouse embryonic fibroblasts; NCL: Neuronal ceroid lipofuscinosis; p: Pro-form;

PGRN: Progranulin protein; pp: Pre-proform; qRT-PCR: Quantitative reverse transcription-polymerase chain reaction; sc: Single chain; SLPI: Secretory leucoprotease inhibitor; TDP-43: TAR DAN binding protein-43;

TFEB: Transcription factor EB

\section{Acknowledgements}

We are thankful to Fargol Mazaheri for her initial help with the NanoString. We thank Sabine Odoy for superb management and maintenance of lab infrastructure and Claudia Ihbe for outstanding technical assistance with mouse colony management.

\section{Funding}

This research was supported by a grant of the NOMIS Foundation to $\mathrm{CH}$ and a PhD stipend of the Hans and Ilse Breuer foundation to AR.

\section{Availability of data and materials}

All data generated or analyzed during this study are included in this published article and its Additional files 1 and 2.

\section{Authors' contributions}

AC, JKG, ST and CH designed the experiments. AVC, JKG and AR did the practical work on isolating microglia for biochemical analysis and JKG with support of AR performed biochemical analysis on microglia. JKG and AC did enzyme activity assays and biochemical analysis on mouse brains. MEF cells were generated by JKG and AC, MEF lines were established by KF and experiments conducted together with GW. AC, JG, AVC and KF analyzed the data. AC and $\mathrm{CH}$ wrote the manuscript with help from JKG. All authors read and approved the final manuscript.

\section{Ethics approval}

No experiments on living animals were conducted for this study. Housing and sacrification of animals as well as use of animal material in this study were performed in accordance with local animal handling laws.

Consent for publication

"Not applicable". 


\section{Competing interests}

C.H. collaborates with Denali Therapeutics. The authors declare that they have no competing interests.

\section{Publisher's Note}

Springer Nature remains neutral with regard to jurisdictional claims in published maps and institutional affiliations.

\section{Author details}

${ }^{1}$ Chair of Metabolic Biochemistry, Biomedical Center (BMC), Faculty of Medicine, Ludwig-Maximilians-Universität München, 81377 Munich, Germany. ${ }^{2}$ German Center for Neurodegenerative Diseases (DZNE) Munich, 81377 Munich, Germany. ${ }^{3}$ Munich Cluster for Systems Neurology (SyNergy), 81377 Munich, Germany.

\section{Received: 7 May 2018 Accepted: 27 August 2018}

\section{Published online: 04 September 2018}

\section{References}

1. Cruts M, Gijselinck I, van der Zee J, Engelborghs S, Wils H, Pirici D, Rademakers R, Vandenberghe R, Dermaut B, Martin JJ, et al. Null mutations in progranulin cause ubiquitin-positive frontotemporal dementia linked to chromosome 17q21. Nature. 2006;442(7105):920-4

2. Baker M, Mackenzie IR, Pickering-Brown SM, Gass J, Rademakers R, Lindholm C, Snowden J, Adamson J, Sadovnick AD, Rollinson S, et al. Mutations in progranulin cause tau-negative frontotemporal dementia linked to chromosome 17. Nature. 2006:442(7105):916-9.

3. Smith KR, Damiano J, Franceschetti S, Carpenter S, Canafoglia L, Morbin M, Rossi G, Pareyson D, Mole SE, Staropoli JF, et al. Strikingly different clinicopathological phenotypes determined by progranulin-mutation dosage. Am J Hum Genet. 2012;90(6):1102-7.

4. Almeida MR, Macario MC, Ramos L, Baldeiras I, Ribeiro MH, Santana I. Portuguese family with the co-occurrence of frontotemporal lobar degeneration and neuronal ceroid lipofuscinosis phenotypes due to progranulin gene mutation. Neurobiol Aging. 2016;41:200 e1-5.

5. Finch N, Baker M, Crook R, Swanson K, Kuntz K, Surtees R, Bisceglio G, Rovelet-Lecrux A, Boeve B, Petersen RC, et al. Plasma progranulin levels predict progranulin mutation status in frontotemporal dementia patients and asymptomatic family members. Brain. 2009;132(3):583-91.

6. Sleegers K, Brouwers N, Van Damme P, Engelborghs S, Gijselinck I, van der Zee J, Peeters K, Mattheijssens M, Cruts M, Vandenberghe R, et al. Serum biomarker for progranulin-associated frontotemporal lobar degeneration. Ann Neurol. 2009;65(5):603-9.

7. Ghidoni R, Benussi L, Glionna M, Franzoni M, Binetti G. Low plasma progranulin levels predict progranulin mutations in frontotemporal lobar degeneration. Neurology. 2008;71(16):1235-9.

8. Carcel-Trullols J, Kovacs AD, Pearce DA. Cell biology of the NCL proteins: what they do and don't do. Biochim Biophys Acta. 2015;1852(10):2242-55.

9. Ahmed Z, Sheng H, Xu YF, Lin WL, Innes AE, Gass J, Yu X, Wuertzer CA, Hou $\mathrm{H}$, Chiba S, et al. Accelerated lipofuscinosis and ubiquitination in granulin knockout mice suggest a role for progranulin in successful aging. Am J Pathol. 2010;177(1):311-24.

10. Wils H, Kleinberger G, Pereson S, Janssens J, Capell A, Van Dam D, Cuijt I, Joris G, De Deyn PP, Haass C, et al. Cellular ageing, increased mortality and FTLD-TDP-associated neuropathology in progranulin knockout mice. J Pathol. 2012;228(1):67-76.

11. Yin F, Banerjee R, Thomas B, Zhou P, Qian L, Jia T, Ma X, Ma Y, ladecola C, Beal $M F$, et al. Exaggerated inflammation, impaired host defense, and neuropathology in progranulin-deficient mice. J Exp Med. 2010;207(1):117-28.

12. Tanaka Y, Chambers JK, Matsuwaki T, Yamanouchi K, Nishihara M. Possible involvement of lysosomal dysfunction in pathological changes of the brain in aged progranulin-deficient mice. Acta Neuropathol Commun. 2014;2:78.

13. Petkau TL, Neal SJ, Milnerwood A, Mew A, Hill AM, Orban P, Gregg J, Lu G, Feldman $\mathrm{HH}$, Mackenzie IR, et al. Synaptic dysfunction in progranulindeficient mice. Neurobiol Dis. 2012;45(2):711-22.

14. Ghoshal N, Dearborn JT, Wozniak DF, Cairns NJ. Core features of frontotemporal dementia recapitulated in progranulin knockout mice. Neurobiol Dis. 2012;45(1):395-408.

15. Gotzl JK, Lang CM, Haass C, Capell A. Impaired protein degradation in FTLD and related disorders. Ageing Res Rev. 2016;32:122-39.
16. Cairns NJ, Neumann M, Bigio EH, Holm IE, Troost D, Hatanpaa KJ, Foong C, White CL 3rd, Schneider JA, Kretzschmar HA, et al. TDP-43 in familial and sporadic frontotemporal lobar degeneration with ubiquitin inclusions. Am J Pathol. 2007:171(1):227-40.

17. Igaz LM, Kwong LK, Xu Y, Truax AC, Uryu K, Neumann M, Clark CM, Elman LB, Miller BL, Grossman M, et al. Enrichment of C-terminal fragments in TAR DNA-binding protein-43 cytoplasmic inclusions in brain but not in spinal cord of frontotemporal lobar degeneration and amyotrophic lateral sclerosis. Am J Pathol. 2008;173(1):182-94.

18. Gotzl JK, Mori K, Damme M, Fellerer K, Tahirovic S, Kleinberger G, Janssens J, van der Zee J, Lang CM, Kremmer E, et al. Common pathobiochemical hallmarks of progranulin-associated frontotemporal lobar degeneration and neuronal ceroid lipofuscinosis. Acta Neuropathol. 2014;127(6):845-60.

19. Ward ME, Chen R, Huang HY, Ludwig C, Telpoukhovskaia M, Taubes A, Boudin $H$, Minami SS, Reichert M, Albrecht $P$, et al. Individuals with progranulin haploinsufficiency exhibit features of neuronal ceroid lipofuscinosis. Sci Transl Med. 2017;9(385):eaah5642.

20. Terlizzi R, Valentino ML, Bartoletti-Stella A, Columbaro M, Piras S, StanzaniMaserati M, Quadri M, Breedveld GJ, Bonifati V, Martinelli P, et al. Muscle ceroid lipofuscin-like deposits in a patient with corticobasal syndrome due to a progranulin mutation. Mov Disord. 2017;32(8):1259-60.

21. Tanaka Y, Suzuki G, Matsuwaki T, Hosokawa M, Serrano G, Beach TG, Yamanouchi K, Hasegawa M, Nishihara M. Progranulin regulates lysosomal function and biogenesis through acidification of lysosomes. Hum Mol Genet. 2017;26(5):969-88.

22. Capell A, Liebscher S, Fellerer K, Brouwers N, Willem M, Lammich S, Gijselinck I, Bittner T, Carlson AM, Sasse F, et al. Rescue of progranulin deficiency associated with frontotemporal lobar degeneration by alkalizing reagents and inhibition of vacuolar ATPase. J Neurosci. 2011;31(5):1885-94.

23. Belcastro $V$, Siciliano $V$, Gregoretti $F$, Mithbaokar $P$, Dharmalingam $G$, Berlingieri S, lorio F, Oliva G, Polishchuck R, Brunetti-Pierri N, et al. Transcriptional gene network inference from a massive dataset elucidates transcriptome organization and gene function. Nucleic Acids Res. 2011;39(20):8677-88.

24. Zhou J, Gao G, Crabb JW, Serrero G. Purification of an autocrine growth factor homologous with mouse epithelin precursor from a highly tumorigenic cell line. J Biol Chem. 1993;268(15):10863-9.

25. Zhu J, Nathan C, Jin W, Sim D, Ashcroft GS, Wahl SM, Lacomis L, ErdjumentBromage $H$, Tempst $P$, Wright $C D$, et al. Conversion of proepithelin to epithelins: roles of SLPI and elastase in host defense and wound repair. Cell. 2002;111(6):867-78.

26. He Z, Bateman A. Progranulin (granulin-epithelin precursor, PC-cell-derived growth factor, acrogranin) mediates tissue repair and tumorigenesis. J Mo Med. 2003:81(10):600-12

27. Xu D, Suenaga N, Edelmann MJ, Fridman R, Muschel RJ, Kessler BM. Novel MMP-9 substrates in cancer cells revealed by a label-free quantitative proteomics approach. Mol Cell Proteomics. 2008;7(11):2215-28.

28. Butler GS, Dean RA, Tam EM, Overall CM. Pharmacoproteomics of a metalloproteinase hydroxamate inhibitor in breast cancer cells: dynamics of membrane type 1 matrix metalloproteinase-mediated membrane protein shedding. Mol Cell Biol. 2008;28(15):4896-914.

29. Bai XH, Wang DW, Kong L, Zhang Y, Luan $Y$, Kobayashi T, Kronenberg HM Yu XP, Liu CJ. ADAMTS-7, a direct target of PTHrP, adversely regulates endochondral bone growth by associating with and inactivating GEP growth factor. Mol Cell Biol. 2009;29(15):4201-19.

30. Kessenbrock K, Frohlich L, Sixt M, Lammermann T, Pfister H, Bateman A, Belaaouaj A, Ring J, Ollert M, Fassler R, et al. Proteinase 3 and neutrophil elastase enhance inflammation in mice by inactivating antiinflammatory progranulin. J Clin Invest. 2008;118(7):2438-47.

31. Lee CW, Stankowski JN, Chew J, Cook CN, Lam YW, Almeida S, Carlomagno $Y$, Lau KF, Prudencio M, Gao FB, et al. The lysosomal protein cathepsin $L$ is a progranulin protease. Mol Neurodegener. 2017;12(1):55.

32. Zhou X, Paushter DH, Feng T, Sun L, Reinheckel T, Hu F. Lysosomal processing of progranulin. Mol Neurodegener. 2017;12(1):62.

33. Hu F, Padukkavidana T, Vaegter CB, Brady OA, Zheng Y, Mackenzie IR, Feldman $\mathrm{HH}$, Nykjaer A, Strittmatter SM. Sortilin-mediated endocytosis determines levels of the frontotemporal dementia protein, progranulin. Neuron. 2010;68(4):654-67.

34. Zhou X, Sun L, Bastos de Oliveira F, Qi X, Brown WJ, Smolka MB, Sun Y, Hu $F$. Prosaposin facilitates sortilin-independent lysosomal trafficking of progranulin. J Cell Biol. 2015;210(6):991-1002.

35. Gowrishankar S, Yuan P, Wu Y, Schrag M, Paradise S, Grutzendler J, De Camilli P, Ferguson SM. Massive accumulation of luminal protease-deficient 
axonal lysosomes at Alzheimer's disease amyloid plaques. Proc Natl Acad Sci U S A. 2015;112(28):E3699-708.

36. Tanaka Y, Matsuwaki T, Yamanouchi K, Nishihara M. Exacerbated inflammatory responses related to activated microglia after traumatic brain injury in progranulin-deficient mice. Neuroscience. 2013;231:49-60.

37. Tanaka Y, Matsuwaki T, Yamanouchi K, Nishihara M. Increased lysosomal biogenesis in activated microglia and exacerbated neuronal damage after traumatic brain injury in progranulin-deficient mice. Neuroscience. 2013;250:8-19.

38. Beel S, Moisse M, Damme M, De Muynck L, Robberecht W, Van Den Bosch L, Saftig P, Van Damme P. Progranulin functions as a cathepsin D chaperone to stimulate axonal outgrowth in vivo. Hum Mol Genet. 2017;26(15):2850-63.

39. Zhou X, Paushter DH, Feng T, Pardon CM, Mendoza CS, Hu F. Regulation of cathepsin D activity by the FTLD protein progranulin. Acta Neuropathol. 2017;134(1):151-3.

40. Chang MC, Srinivasan K, Friedman BA, Suto E, Modrusan Z, Lee WP, Kaminker JS, Hansen DV, Sheng M. Progranulin deficiency causes impairment of autophagy and TDP-43 accumulation. J Exp Med. 2017;214(9):2611-28.

41. Holler CJ, Taylor G, Deng Q, Kukar T. Intracellular proteolysis of Progranulin generates stable, lysosomal Granulins that are Haploinsufficient in patients with frontotemporal dementia caused by GRN mutations. eNeuro. 2017;4(4)

42. Kayasuga Y, Chiba S, Suzuki M, Kikusui T, Matsuwaki T, Yamanouchi K, Kotaki H, Horai R, Iwakura Y, Nishihara M. Alteration of behavioural phenotype in mice by targeted disruption of the progranulin gene. Behav Brain Res. 2007;185(2):110-8.

43. Saftig P, Hetman M, Schmahl W, Weber K, Heine L, Mossmann H, Koster A, Hess B, Evers M, von Figura K, et al. Mice deficient for the lysosomal proteinase cathepsin D exhibit progressive atrophy of the intestinal mucosa and profound destruction of lymphoid cells. EMBO J. 1995;14(15):3599-608.

44. Sharpless NE. Preparation and immortalization of primary murine cells. Cell Biology, Four-Volume Set. 2006:223-8.

45. Medina DL, Di Paola S, Peluso I, Armani A, De Stefani D, Venditti R, Montefusco S, Scotto-Rosato A, Prezioso C, Forrester A, et al. Lysosomal calcium signalling regulates autophagy through calcineurin and TFEB. Nat Cell Biol. 2015;17(3):288-99.

46. Sardiello M, Palmieri M, di Ronza A, Medina DL, Valenza M, Gennarino VA, Di Malta C, Donaudy F, Embrione V, Polishchuk RS, et al. A gene network regulating lysosomal biogenesis and function. Science. 2009;325(5939):473-7.

47. Palmieri M, Impey S, Kang H, di Ronza A, Pelz C, Sardiello M, Ballabio A. Characterization of the CLEAR network reveals an integrated control of cellular clearance pathways. Hum Mol Genet. 2011;20(19):3852-66.

48. Pena-Llopis S, Vega-Rubin-De-Celis S, Schwartz JC, Wolff NC, Tran TA, Zou L, Xie XJ, Corey DR, Brugarolas J. Regulation of TFEB and V-ATPases by mTORC1. EMBO J. 2011;30(16):3242-58.

49. Klein A, Henseler M, Klein C, Suzuki K, Harzer K, Sandhoff K. Sphingolipid activator protein $D$ (sap-D) stimulates the lysosomal degradation of ceramide in vivo. Biochem Biophys Res Commun. 1994;200(3):1440-8.

50. Settembre C, Di Malta C, Polito VA, Garcia Arencibia M, Vetrini F, Erdin S, Erdin SU, Huynh T, Medina D, Colella P, et al. TFEB links autophagy to lysosomal biogenesis. Science. 2011;332(6036):1429-33.

51. Klein ZA, Takahashi H, Ma M, Stagi M, Zhou M, Lam TT, Strittmatter SM. Loss of TMEM106B ameliorates lysosomal and frontotemporal dementia-related phenotypes in Progranulin-deficient mice. Neuron. 2017;95(2):281-296 e6.

52. Taggart CC, Lowe GJ, Greene CM, Mulgrew AT, O'Neill SJ, Levine RL, McElvaney NG. Cathepsin B, L, and S cleave and inactivate secretory leucoprotease inhibitor. J Biol Chem. 2001;276(36):33345-52.

53. Erickson $\mathrm{AH}$. Biosynthesis of lysosomal endopeptidases. J Cell Biochem. 1989;40(1):31-41.

54. Caporaso GL, et al. Chloroquine inhibits intracellular degradation but not secretion of Alzheimer beta/A4 amyloid precursor protein. Proc Natl Acad Sci. 1992:89(6):2252-6.

55. Golde TE, et al. Processing of the amyloid protein precursor to potentially amyloidogenic derivatives. Science. 1992;255(5045):728-30.

56. Haass C, et al. Targeting of cell-surface beta-amyloid precursor protein to lysosomes: alternative processing into amyloid-bearing fragments. Nature. 1992;357(6378):500-3.

57. Xiao Q, et al. Neuronal-Targeted TFEB Accelerates Lysosomal Degradation of APP, Reducing Abeta Generation and Amyloid Plaque Pathogenesis. J Neurosci. 2015;35(35):12137-51.

58. Zhang Y, Chen K, Sloan SA, Bennett ML, Scholze AR, O'Keeffe S, Phatnani HP, Guarnieri P, Caneda C, Ruderisch N, et al. An RNA-sequencing transcriptome and splicing database of glia, neurons, and vascular cells of the cerebral cortex. J Neurosci. 2014;34(36):11929-47.
59. Lui H, Zhang J, Makinson SR, Cahill MK, Kelley KW, Huang HY, Shang Y, Oldham MC, Martens LH, Gao F, et al. Progranulin deficiency promotes circuit-specific synaptic pruning by microglia via complement activation. Cell. 2016;165(4):921-35.

60. Evers BM, Rodriguez-Navas C, Tesla RJ, Prange-Kiel J, Wasser CR, Yoo KS, McDonald J, Cenik B, Ravenscroft TA, Plattner F, et al. Lipidomic and transcriptomic basis of lysosomal dysfunction in Progranulin deficiency. Cell Rep. 2017;20(11):2565-74.

61. Stoka $V$, Turk $V$, Turk B. Lysosomal cathepsins and their regulation in aging and neurodegeneration. Ageing Res Rev. 2016;32:22-37.

62. Arrant $A E$, Onyilo VC, Unger DE, Roberson ED. Progranulin gene therapy improves lysosomal dysfunction and microglial pathology associated with frontotemporal dementia and neuronal ceroid Lipofuscinosis. J Neurosci. 2018;38(9):2341-58.

63. Petkau TL, Blanco J, Leavitt BR. Conditional loss of progranulin in neurons is not sufficient to cause neuronal ceroid lipofuscinosis-like neuropathology in mice. Neurobiol Dis. 2017;106:14-22.

64. Petkau TL, Kosior N, de Asis K, Connolly C, Leavitt BR. Selective depletion of microglial progranulin in mice is not sufficient to cause neuronal ceroid lipofuscinosis or neuroinflammation. J Neuroinflammation. 2017;14(1):225.

65. Berti PJ, Storer AC. Alignment/phylogeny of the papain superfamily of cysteine proteases. J Mol Biol. 1995;246(2):273-83.

66. Butts CT, Zhang X, Kelly JE, Roskamp KW, Unhelkar MH, Freites JA, Tahir S, Martin RW. Sequence comparison, molecular modeling, and network analysis predict structural diversity in cysteine proteases from the cape sundew, Drosera capensis. Comput Struct Biotechnol J. 2016:14:271-82.

67. Richau KH, Kaschani F, Verdoes M, Pansuriya TC, Niessen S, Stuber K, Colby T, Overkleeft HS, Bogyo M, Van der Hoorn RA. Subclassification and biochemical analysis of plant papain-like cysteine proteases displays subfamily-specific characteristics. Plant Physiol. 2012;158(4):1583-99.

68. Gu C, Shabab M, Strasser R, Wolters PJ, Shindo T, Niemer M, Kaschani F, Mach L, van der Hoorn RA. Post-translational regulation and trafficking of the granulin-containing protease RD21 of Arabidopsis thaliana. PLoS One. 2012;7(3):e32422.

69. Yamada K, Matsushima R, Nishimura M, Hara-Nishimura I. A slow maturation of a cysteine protease with a granulin domain in the vacuoles of senescing Arabidopsis leaves. Plant Physiol. 2001;127(4):1626-34.

70. Kleinberger G, Brendel M, Mracsko E, Wefers B, Groeneweg L, Xiang X, Focke C, Deussing M, Suarez-Calvet M, Mazaheri F, et al. The FTD-like syndrome causing TREM2 T66M mutation impairs microglia function, brain perfusion, and glucose metabolism. EMBO J. 2017;36(13):1837-53.

71. Keren-Shaul H, Spinrad A, Weiner A, Matcovitch-Natan O, Dvir-Szternfeld R, Ulland TK, David E, Baruch K, Lara-Astaiso D, Toth B, et al. A unique microglia type associated with restricting development of Alzheimer's disease. Cell. 2017;169(7):1276-90.

Ready to submit your research? Choose BMC and benefit from:

- fast, convenient online submission

- thorough peer review by experienced researchers in your field

- rapid publication on acceptance

- support for research data, including large and complex data types

- gold Open Access which fosters wider collaboration and increased citations

- maximum visibility for your research: over $100 \mathrm{M}$ website views per year

At $\mathrm{BMC}$, research is always in progress.

Learn more biomedcentral.com/submissions 